\title{
Warm and Dry Spells (WDS) in Austral Winter over Central South America
}

\author{
P. Satyamurty, M. da Silva Teixeira, and C. Klug Padilha \\ Centro de Previsão de Tempo e Estudos Climáticos (CPTEC), Instituto Nacional de Pesquisas Espaciais (INPE), Av. \\ Astronautas, No. 1758, São José dos Campos, SP, CEP: 12.245-970, Brazil
}

Received: 22 December 2006 - Revised: 11 April 2007 - Accepted: 7 May 2007 - Published: 4 June 2007

\begin{abstract}
The horizontal and vertical structure of unusually warm and dry spells (WDS) over the central parts of South America during the winter and post-winter months (JJAS) are studied. During WDS the mean temperature and humidity anomalies over central Brazil are about $+4.1^{\circ} \mathrm{C}$ and $-13.2 \%$, respectively. The mean duration of WDS is 11 days and their mean frequency is less than one per year during the months of JJAS. Apparently, WDS have no preference for the phase of ENSO. Widespread and persistent subsidence in the middle troposphere is observed in tropical Brazil during WDS, which renders the lower tropospheric air warm and dry. The negative anomalies of the specific humidity are observed to be associated with the subsidence regions. A strong, slow moving ridge in the eastern South Pacific and a low-pressure center in northern Argentina are important surface characteristics during the WDS. A more detailed investigation of two specific WDS events, a strong event (August-September 1999) and a moderate one (June 2002), shows a blockinglike situation in the 500-hPa geopotential and surface pressure fields in the Pacific. The South Atlantic subtropical high somewhat approaches the continent. Strong northerlies over the central and eastern parts of Brazil are also observed in the lower troposphere. During WDS the regional circulation acquires summertime characteristics, except for the absence of precipitation, and the circulation in the meridional plane is in the opposite sense from the Hadley circulation. A frontal system, supported by a $500-\mathrm{hPa}$ trough, advances into central Brazil, causing the dissipation of the anomalous situation.
\end{abstract}

Keywords. Hydrology (Drought) - Atmospheric composition and structure (Biosphere-atmosphere interactions; Thermosphere - composition and chemistry)

\section{Introduction}

In the central parts of Brazil and the adjoining countries in South America the winter and post-winter months (June through September, JJAS) present warm and dry spells (WDS) of one or two weeks in duration and are locally called "veranicos", which means literally little summers (Satyamurty et al., 1998). The atmospheric humidity in this region reaches its minimum in winter (DNMET, 1992) and when the temperature rises anomalously above the climatological mean during warm spells the relative humidity drops to levels below 40\%. Although the meteorologists in Brazil know the phenomenon, there have been very few systematic studies of the WDS and their environmental impacts (Assad et al., 1993).

The WDSs are part of the intraseasonal variability in the atmospheric conditions over South America. An understanding of the physical and dynamical characteristics of these phenomena is a first step to improve medium-range weather forecasts in the region. A second motivation for the present study is the general discomfort experienced by the population and the rise of vegetation fires in central Brazil, reported widely in the media, during the WDSs.

The objectives of the present study are (1) to describe the synoptic scale and regional scale meteorological conditions associated with the WDSs in the central parts of South America, with special attention to the central parts of Brazil, and (2) to obtain a climatology of those events and some insights into the possible mechanisms of their formation and dissipation. The importance of the present study arises from the fact that the WDSs may influence human comfort (Braga et al., 2000) and vegetation fires in the region.

Correspondence to: P. Satyamurty

(saty@cptec.inpe.br)

Published by Copernicus GmbH on behalf of the European Geosciences Union. 


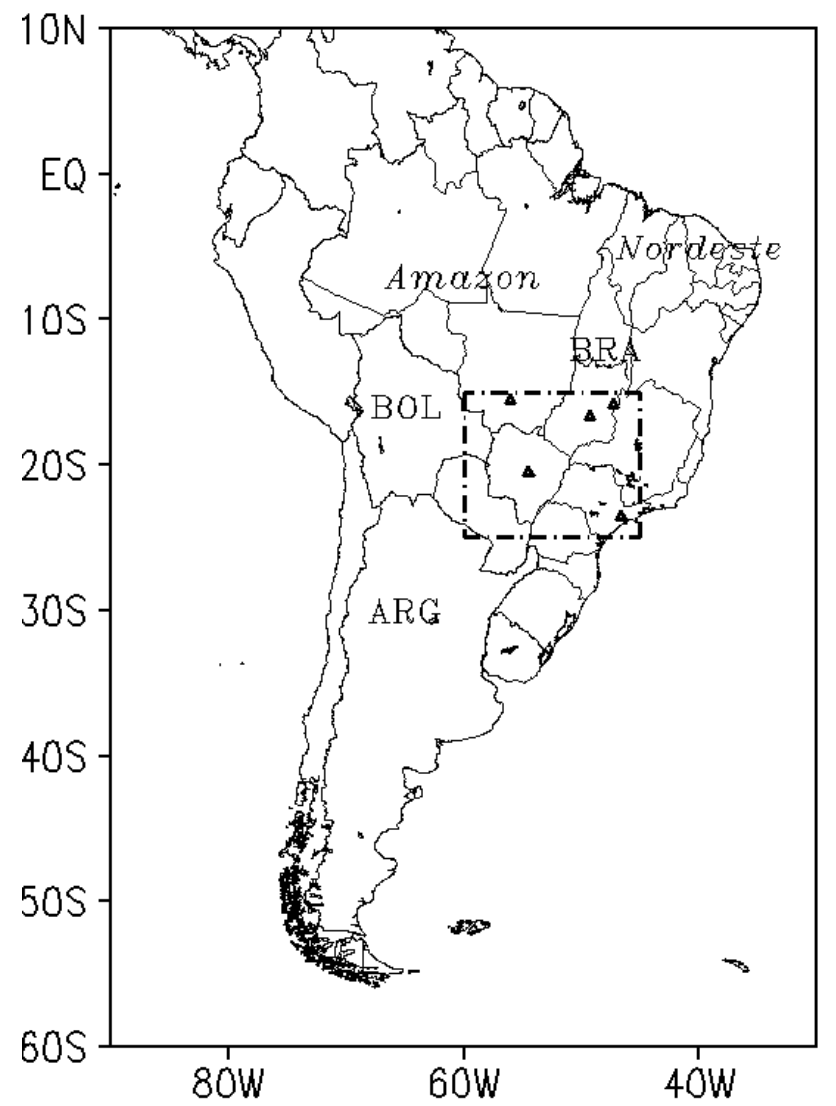

Fig. 1. Locator map. BRA: Brazil, ARG: Argentina, BOL: Bolivia. The Amazon (Amazon) and Northeast Brazil (Nordeste) are indicated. The rectangle is the target area. Deltas mark the 5 major cities where the surface temperature observations are compared with the NCEP/NCAR data.

\section{Data and methodology}

\subsection{Identification of WDS}

The National Centers for Environmental Prediction (NCEP)/National Center for Atmospheric Research (NCAR) reanalysis grid point data sets with $2.5^{\circ}$ latitude $\times 2.5^{\circ}$ longitude resolution for 00:00 UTC for the period 1961-2003 are used in this study. In order to identify the WDSs that affect the central parts of Brazil, a target area bounded by $13.75^{\circ} \mathrm{S}, 26.25^{\circ} \mathrm{S}$ and $43.75^{\circ} \mathrm{W}, 61.25^{\circ} \mathrm{W}$ is considered and is shown in Fig. 1. The target area has 35 horizontal grid points and is big enough to represent central Brazil and it contains many state capitals away from the coast, such as Brasilia, Sao Paulo, Goiania, Cuiaba and Campo Grande, and where nearly $30 \%$ of Brazil's population lives.

The area-averaged 00:00 UTC surface temperature (more precisely $1000 \mathrm{hPa}$ temperature) over the target area, i.e. averaged over the 35 grid points, is designated here as $\mathrm{T}$. The corresponding monthly climatological value averaged over the target area is designated as $\mathrm{T}_{c}$ and is a function of the

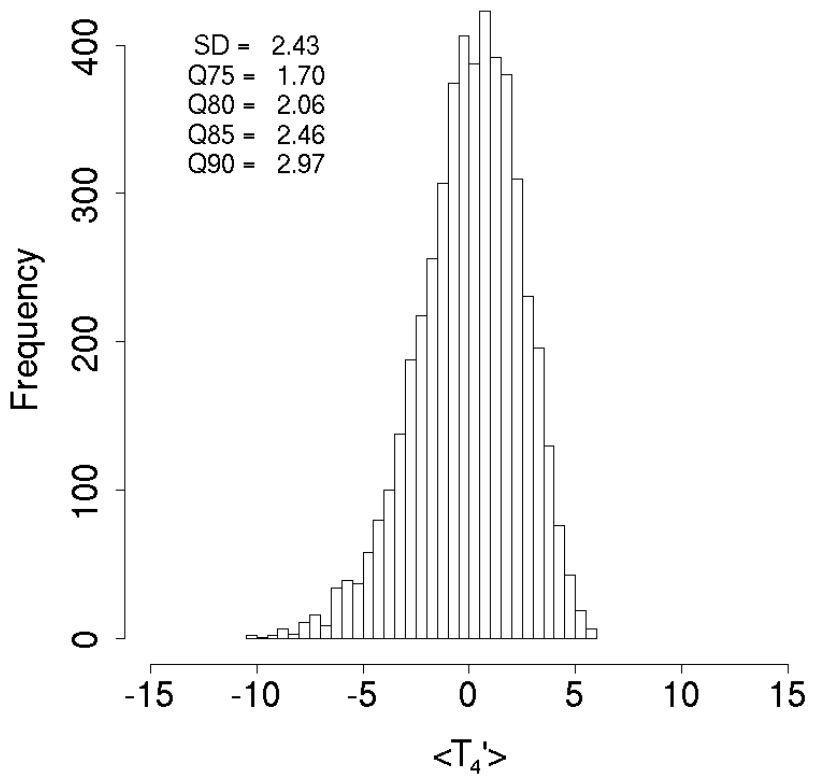

(a)

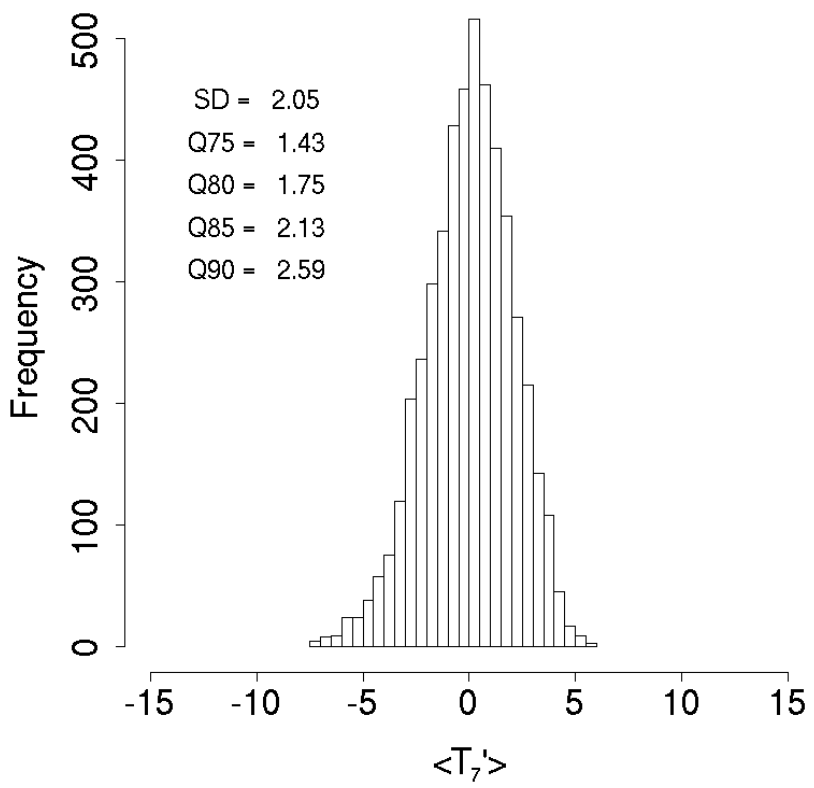

(b)

Fig. 2. Frequency distributions of the mean temperature anomalies over the target area (a) 4-day averaged anomaly and (b) weekly averaged anomaly. SD is standard deviation. Q75, Q80, Q85, Q90 are the percentile values at $75 \%, 80 \%, 85 \%$, and $90 \%$ level. $\left({ }^{\circ} \mathrm{C}\right)$.

month of the year. For a given month $\mathrm{T}_{c}$ is obtained by averaging the 00:00 UTC surface temperature over the same 40 calendar months in the period 1961 through 2000. The anomaly $\mathrm{T}^{\prime}$ is given by $\mathrm{T}-\mathrm{T}_{c}$. $\mathrm{T}^{\prime}$ is a function of day only (not a function of grid point) and is the daily 00:00 UTC 
Table 1. Characteristics of Warm and Dry Spells (WDS) in the period 1961-2003. BEGIN: beginning date. DUR: duration in days. $\left\langle T^{\prime}\right\rangle$, $\left\langle\mathrm{r}^{\prime}\right\rangle,\left\langle\mathrm{q}^{\prime}\right\rangle$ : episode-mean anomalies averaged over the target area of temperature, relative humidity and specific humidity, respectively, at $1000 \mathrm{hPa}$. SI: severity index. EN, LN, N indicate ENSO phases, El Niño, La Niña and normal years, respectively. RANK is the order of the event in terms of SI. WDSs used in case studies are shaded.

\begin{tabular}{|c|c|c|c|c|c|c|c|c|}
\hline CASE & BEGIN & DUR (days) & $\left\langle\mathrm{T}^{\prime}\right\rangle\left({ }^{\circ} \mathrm{C}\right)$ & $\left\langle\mathrm{r}^{\prime}\right\rangle(\%)$ & $\left\langle\mathrm{q}^{\prime}\right\rangle(\mathrm{g} / \mathrm{kg})$ & SI & ENSO & RANK \\
\hline 1 & 17 Aug 1961 & 19 & 3.8 & -13.6 & -1.0 & 8.1 & $\mathrm{~N}$ & 2 \\
\hline 2 & 10 Sep 1961 & 14 & 4.4 & -10.1 & 0.1 & 5.1 & $\mathrm{~N}$ & 8 \\
\hline 3 & 2 Sep 1962 & 8 & 4.6 & -22.1 & -2.8 & 4.4 & $\mathrm{~N}$ & 12 \\
\hline 4 & 11 July 1963 & 12 & 4.4 & -20.5 & -1.7 & 6.2 & EN & 4 \\
\hline 5 & 20 Aug 1963 & 21 & 4.9 & -18.3 & -1.7 & 11.5 & $\mathrm{EN}$ & 1 \\
\hline 6 & 22 Sep 1963 & 9 & 4.1 & -18.8 & -2.3 & 4.3 & $\mathrm{EN}$ & 13 \\
\hline 7 & 25 Aug 1964 & 9 & 3.7 & -11.3 & -0.5 & 3.1 & $\mathrm{LN}$ & 23 \\
\hline 8 & 25 Aug 1965 & 12 & 3.5 & -16.1 & -1.7 & 5.2 & $\mathrm{EN}$ & 6 \\
\hline 9 & 9 Sep 1966 & 8 & 4.2 & -10.6 & -0.1 & 2.7 & $\mathrm{~N}$ & 28 \\
\hline 10 & 12 Aug 1967 & 12 & 4.1 & -12.0 & -0.3 & 4.6 & $\mathrm{~N}$ & 10 \\
\hline 11 & 30 Aug 1967 & 11 & 3.9 & -18.7 & -2.1 & 5.2 & $\mathrm{~N}$ & 7 \\
\hline 12 & 12 Aug 1969 & 9 & 3.6 & -13.8 & -1.0 & 3.5 & $\mathrm{EN}$ & 18 \\
\hline 13 & 10 Sep 1969 & 11 & 4.8 & -18.8 & -2.0 & 5.8 & $\mathrm{EN}$ & 5 \\
\hline 14 & 23 Sep 1969 & 8 & 4.8 & -16.7 & -0.9 & 3.5 & EN & 19 \\
\hline 15 & 25 Sep 1970 & 9 & 3.9 & -12.5 & -0.5 & 3.0 & $\mathrm{LN}$ & 25 \\
\hline 16 & 21 July 1971 & 10 & 3.4 & -16.4 & -1.3 & 4.0 & $\mathrm{LN}$ & 15 \\
\hline 17 & 3 June 1972 & 12 & 3.8 & -9.0 & 1.1 & 3.4 & $\mathrm{EN}$ & 20 \\
\hline 18 & 25 Aug 1974 & 8 & 3.8 & -6.2 & 0.9 & 1.9 & $\mathrm{LN}$ & 32 \\
\hline 19 & 24 July 1976 & 8 & 3.3 & -6.6 & 0.9 & 1.8 & $\mathrm{EN}$ & 33 \\
\hline 20 & 12 June 1984 & 15 & 3.4 & -8.8 & 0.6 & 4.2 & $\mathrm{LN}$ & 14 \\
\hline 21 & 7 July 1987 & 13 & 4.7 & -4.0 & 2.3 & 3.3 & $\mathrm{EN}$ & 21 \\
\hline 22 & 24 Aug 1988 & 9 & 3.9 & -15.6 & -1.4 & 3.9 & $\mathrm{LN}$ & 17 \\
\hline 23 & 21 Sep 1988 & 8 & 5.0 & -13.2 & 0.1 & 3.2 & $\mathrm{LN}$ & 22 \\
\hline 24 & 26 June 1993 & 11 & 4.8 & -12.3 & 0.8 & 4.0 & $\mathrm{EN}$ & 16 \\
\hline 25 & 9 Aug 1995 & 8 & 4.4 & -8.6 & 0.6 & 2.5 & $\mathrm{LN}$ & 29 \\
\hline 26 & 26 Aug 1995 & 9 & 4.5 & -17.5 & -1.5 & 4.4 & $\mathrm{LN}$ & 11 \\
\hline 27 & 19 June 1997 & 9 & 4.2 & -5.9 & 1.9 & 2.3 & $\mathrm{EN}$ & 30 \\
\hline 28 & 2 Sep 1997 & 10 & 4.7 & -19.3 & -1.8 & 5.0 & EN & 9 \\
\hline 29 & 27 Aug 1999 & 14 & 4.0 & -17.3 & -1.7 & 6.7 & $\mathrm{LN}$ & 3 \\
\hline 30 & 8 June 2000 & 9 & 2.9 & -9.6 & 0.0 & 2.3 & $\mathrm{LN}$ & 31 \\
\hline 31 & $21 \mathrm{Aug} 2000$ & 8 & 4.4 & -12.2 & -0.5 & 3.0 & $\mathrm{LN}$ & 24 \\
\hline 32 & 2 June 2002 & 10 & 4.0 & -11.2 & 0.5 & 2.9 & EN & 26 \\
\hline 33 & 12 Aug 2002 & 9 & 3.3 & -9.4 & -0.3 & 2.8 & EN & 27 \\
\hline MEAN & & 11 & 4.1 & -13.2 & -0.5 & 4.2 & & \\
\hline
\end{tabular}

area-mean temperature anomaly over the target area. There are 4880 values of $\mathrm{T}^{\prime}$ over the 40 seasons of June through September (JJAS) in the period 1961-2000. We are interested in identifying anomalous warm spells that persist for several days. Thus, from the values of $\mathrm{T}^{\prime}, 4$-day and 7-day running average temperature anomalies over the target area, $\mathrm{T}_{4}^{\prime}$ and $\mathrm{T}_{7}^{\prime}$, respectively, are obtained.

In the case of 7-day running means $\left(\mathrm{T}_{7}^{\prime}\right)$ we have considered the data from 29 May through 3 October over the 40 years to have 4880 values, and for $\mathrm{T}_{4}^{\prime}$ the daily data from 30 May through 2 Oct are considered. The frequency distributions of $\mathrm{T}_{4}^{\prime}$ and $\mathrm{T}_{7}^{\prime}$ are constructed and their respective standard deviations, $\sigma\left(\mathrm{T}_{4}^{\prime}\right)$ and $\sigma\left(\mathrm{T}_{7}^{\prime}\right)$, and percentiles are ob- tained. The frequency distributions are shown in Fig. 2. The standard deviations of $\mathrm{T}_{4}^{\prime}$ and $\mathrm{T}_{7}^{\prime}$ are $2.43^{\circ} \mathrm{C}$ and $2.05^{\circ} \mathrm{C}$, respectively, which correspond to approximately the 85 th percentiles of the respective distributions. The threshold values of $\mathrm{T}_{4}^{\prime}$ and $\mathrm{T}_{7}^{\prime}$ for the identification of WDS are based on these statistics. The exact procedure for the identification of the warm spells is given below.

In JJAS (austral winter and post-winter season) $\mathrm{T}^{\prime}$ series, the daily temperature anomalies averaged over the target area given in Fig. 1, are examined. All the periods of 7 consecutive days or longer over which $\mathrm{T}^{\prime}$ is greater than $2.0^{\circ} \mathrm{C}$ (approximately one $\sigma\left(\mathrm{T}_{7}^{\prime}\right)$ ) are identified. All these periods are candidates for warm spells. If, within such a period, there 


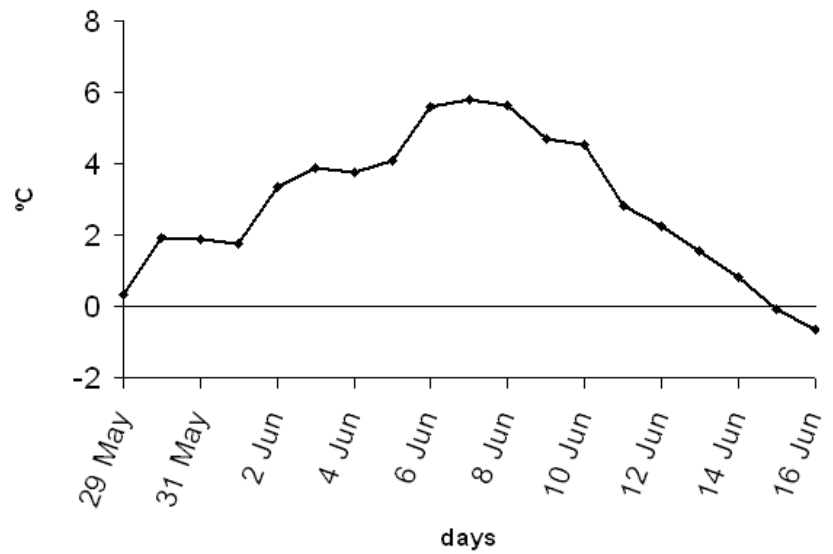

Fig. 3. Area mean temperature anomaly $\left({ }^{\circ} \mathrm{C}\right)$ for the period 29 May-16 June 2002. Mean is obtained over 35 grid points in the target area shown in Fig. 1.

are 4 consecutive days with $\mathrm{T}^{\prime} \geq 2.5^{\circ} \mathrm{C}$ (approximately one $\left.\sigma\left(\mathrm{T}_{4}^{\prime}\right)\right)$, the period is designated as a warm spell. This means that during a warm spell there is at least one period of 4 consecutive days on which the area-mean temperature anomaly is greater than or equal to $2.5^{\circ} \mathrm{C}$. When an episode is identified at the beginning of June, the last week of May is also examined to obtain the full duration of the episode. Similarly when an episode is identified at the end of the month of September the first week of October is also examined to include the full duration of the episode. The warm spell duration in days (n) is the number of consecutive days in which $\mathrm{T}^{\prime} \geq 2.0^{\circ} \mathrm{C}$.

The above criterion is based solely on temperature anomaly. For all such episodes the corresponding mean relative humidity anomaly and the specific humidity anomaly at the 1000-hPa level, $\mathrm{r}^{\prime}$ and $\mathrm{q}^{\prime}$, averaged over the target area, are calculated for all the days of the warm spells. From the daily values of $\mathrm{T}^{\prime}, \mathrm{r}^{\prime}$, and $\mathrm{q}^{\prime}$ the episode averages (mean of the variable over the $\mathrm{n}$ days), $\left\langle\mathrm{T}^{\prime}\right\rangle,\left\langle\mathrm{r}^{\prime}\right\rangle$ and $\left\langle\mathrm{q}^{\prime}\right\rangle$, are calculated and are used to characterize the warm spells. For the purpose of determining the climatology we used 40-year data from 1961 through 2000. However, the warm spells are identified in the 43-year period 1961-2003.

Table 1 shows all the warm spells identified in the period 1961 through 2003 in the months of June through September. We note that, although the criterion for the identification of warm spells is based on temperature anomalies alone, the episode-mean relative humidity anomalies averaged over the target area are negative in all of the 33 cases identified. Hence, we designate these episodes as Warm and Dry Spells (WDSs).

An example is necessary for an understanding of the criteria used for the identification of the WDSs. The temperature anomaly, $\mathrm{T}^{\prime}$, in the period 29 May through 16 June 2002 is shown in Fig. 3. According to the criteria given above in

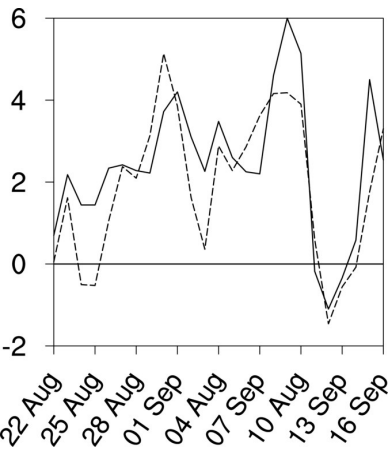

(a)

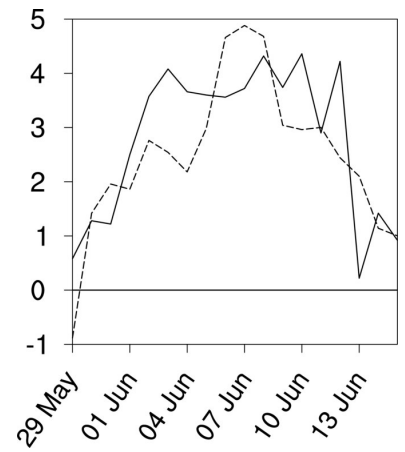

(b)
Fig. 4. Evolution of temperature anomaly for (a) 20 August through 16 September 1999, and (b) 20 May through 21 June 2002 (see Table 1). Continuous line: obtained from surface observations in the target area. Broken line: obtained from NCEP reanalysis values in the grid boxes around the surface stations. WDS cases 29 and 32 (Table 1) are contained in the periods shown in panels (a) and (b), respectively.

this section, the period 2 June through 11 June is a warm spell and, from the $\mathrm{r}^{\prime}$ values given in Table 1 (Case 32), we identify it as a WDS. This spell persists for 10 days and the daily mean temperature anomaly is higher than $2.5^{\circ} \mathrm{C}$ on 9 consecutive days, the episode mean temperature anomaly is $4.0^{\circ} \mathrm{C}$, and the episode-mean relative humidity is $11 \%$ less than normal.

We have checked the suitability of the data sets used in this study by comparing the average temperature anomalies obtained from the NCEP data with those obtained from the synoptic station data from the state capitals mentioned in the first paragraph of this section. We have used the NCEP data in the grid boxes containing the stations for the calculation of the NCEP-temperature anomaly. The synoptic observations are used to obtain the station-temperature anomaly with respect to the 1961-1990 climatological values (DNMET, 1992). Both are presented in Fig. 4 for two cases of WDS (cases 29 and 32 in Table 1). It can be seen that the evolution of the temperature anomaly obtained from the NCEP data agrees very well with that obtained from observations.

\subsection{Severity of WDS}

A measure for the severity of the WDS is necessary to permit comparisons among episodes. A nondimensional index for measuring the severity of the WDS is designed for this purpose, taking into account the duration, the episode mean temperature anomaly and the episode mean relative humidity anomaly, and is given by:

$\mathrm{SI}=\left(1 / T_{c}\right) \Sigma T^{\prime}-\left(1 / r_{c}\right) \Sigma r^{\prime}$,

where $T_{c}$ and $r_{c}$ are mean climatological values of temperature $\left({ }^{\circ} \mathrm{C}\right)$ and relative humidity $(\%)$ over the target area for 
the month of the episode. The summations in Eq. (1) are over the $\mathrm{n}$ days (duration) of the WDS. If a WDS has a few days in one month and a few in the next or previous month, a weighted average of the climatological temperatures, Tc, of the two months is used in Eq. (1). The index is simply the sum of the normalized positive anomalies of temperature in ${ }^{\circ} \mathrm{C}$ and normalized negative anomalies of relative humidity in percentage points. It is easy to see from Eq. (1) that SI is higher for longer WDS episodes.

Based on the SI values the episodes can be categorized into two classes, strong and moderate WDS, each one containing approximately $50 \%$ of the events. The strong events have $\mathrm{SI} \geq 3.9$ and the moderate ones have $\mathrm{SI}<3$.9. The WDS shown in Fig. 3 is a moderate event.

\subsection{Compositing}

Episode mean fields of surface temperature, surface pressure, 500-hPa geopotential, $850-\mathrm{hPa}$ humidity, $850-\mathrm{hPa}$ winds, 250-hPa winds, 500-hPa vertical velocity and their anomalies are obtained over South America and adjoining seas by averaging 00:00 UTC daily fields over the duration of the WDS in consideration. Composites of meteorological fields of the WDSs and the anomalies are obtained by averaging the episode-mean fields over the 17 strong WDS cases. These fields serve to represent the average characteristics of those WDSs. It should be remembered, at the time of examining the composites, that the individual WDS are all not identical and, therefore, the averaging process will reduce the intensity of the composite anomaly fields.

\subsection{Diagnostics}

The thermal advection in the lower troposphere $(850 \mathrm{hPa}$ and $700 \mathrm{hPa}$ ) is calculated over South America for a period covering all the days of the WDS and a few days immediately before and after the episode, using the expression $-[u(\partial \theta / \partial \mathrm{x})+v(\partial \theta / \partial \mathrm{y})]$, where $u, v, \theta$ are the zonal and meridional wind components and potential temperature, respectively. Similarly, the adiabatic heating and cooling of the lower troposphere due to vertical motion is calculated, using the expression $-\omega(\partial \theta / \partial p)$, where $\omega$ is vertical velocity. These fields will enable us to compare the effects of adiabatic heating due to vertical motion with the effects of horizontal thermal advection.

The horizontal and vertical advections of humidity in the lower troposphere are calculated using the expressions $-[u(\partial \mathrm{q} / \partial \mathrm{x})+v(\partial \mathrm{q} / \partial \mathrm{y})]$ and $-\omega \partial \mathrm{q} / \partial \mathrm{p}$, respectively. These calculations will enable us to appreciate the effects of subsidence on drying the lower troposphere compared to the effects of horizontal advection of water vapor flux.

\section{General characteristics of WDS}

\subsection{Duration and intensity}

Table 1 shows that, on the average, the frequency of the WDSs in the months of JJAS is about 0.8 cases per year (33 cases in 43 years). The average duration of the WDSs is 11 days and the mean temperature and the humidity anomalies during the episodes are found to be $4.1^{\circ} \mathrm{C}$ and $-13.2 \%$, respectively. The mean specific humidity anomaly is small $\left(-0.5 \mathrm{~g} \mathrm{~kg}^{-1}\right)$. In some WDSs the average relative humidity anomaly is as low as $-20 \%$.

According to Table 1, there are nine cases with SI values greater than or equal to 5.0. The August-September 1963 event (Case 5) is the severest WDS with a duration of 21 days and the episode-mean temperature anomaly over the target area is $+4.9^{\circ} \mathrm{C}$ and the humidity anomaly is $-18.3 \%$. The weakest WDS is registered in July 1976 during which the average temperature anomaly is $3.3^{\circ} \mathrm{C}$. Its duration is just 8 days. The relative humidity is only $6.6 \%$ lower than normal. Actually the specific humidity anomaly is positive in this case. Its SI value is 1.8. In 22 cases the specific humidity anomaly is also negative, suggesting the effects of subsidence and horizontal advection of dry air. In the remaining eleven cases the specific humidity anomaly over the target area is positive, however, the relative humidity anomaly is negative.

Some interannual variability in the frequency of occurrence and the severity of the WDS can be seen in Table 1 . The years 1963 and 1969 present three episodes each. Eleven of the 43 years do not present any case. The decadal distribution of the events shows large variability. Fourteen out of 33 events are identified in the 1960s and the rest of the events are distributed over the three recent decades.

ENSO phases are indicated in the last column of the table. There are 15 WDSs in the El Niño years, 12 in the La Niña years and 6 in the neutral years. The distribution and intensity of WDS do not show any definite relation with the ENSO phase. This suggests that WDS is more a result of regional scale and synoptic scale perturbations. These aspects are presented in Sect. 4.

\subsection{Composite fields}

Composite fields of a phenomenon offer a coherent picture of the average characteristics of that phenomenon. The composites of the fields of some important meteorological variables for the strong WDS cases are presented here. Figure 5 shows the fields of temperature anomaly, relative humidity anomaly and the specific humidity anomaly at the $1000-\mathrm{hPa}$ level and the 500-hPa vertical velocity $(\omega)$. We note that the region of positive temperature anomaly in the composite field (mean of the 17 strong WDSs) occupies a large area in central South America over Paraguay, western and southern Brazil, northern Argentina and Bolivia (Fig. 5a). In the center of 


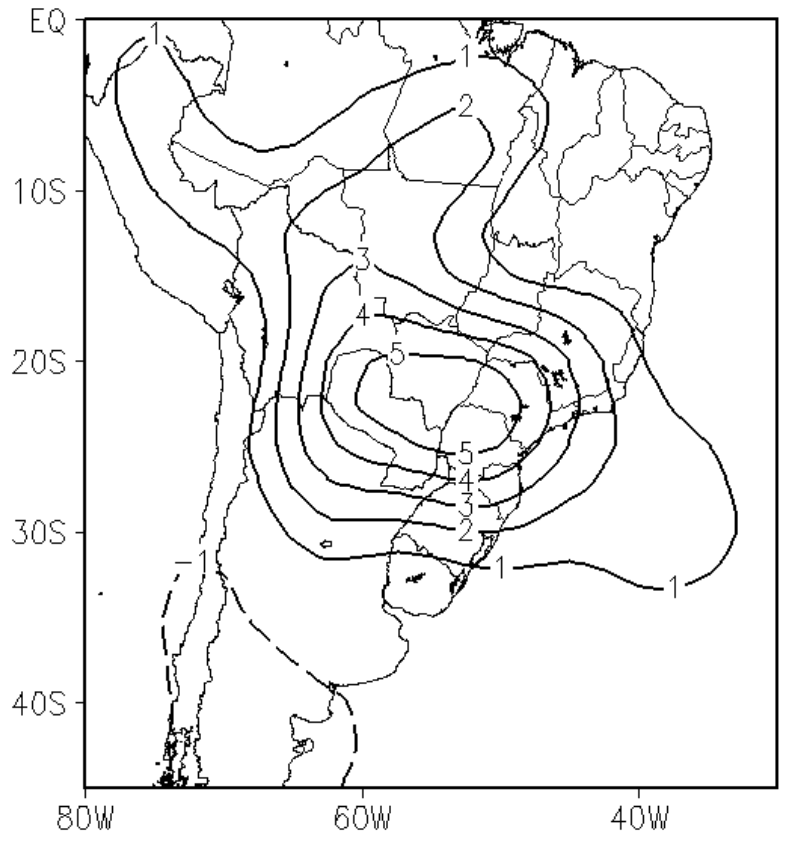

(a)

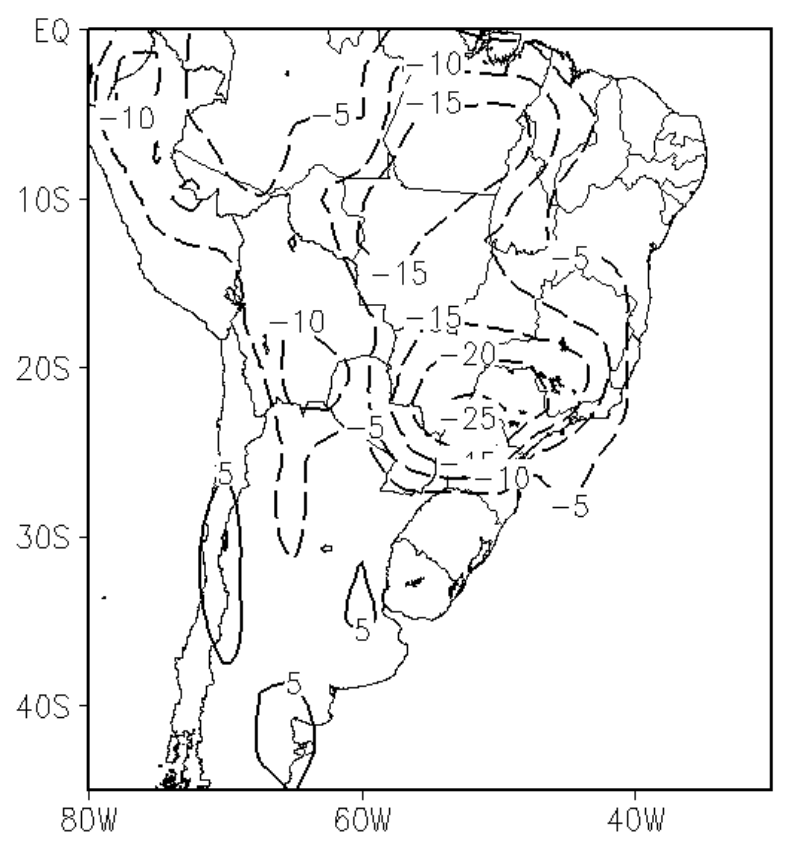

(b)

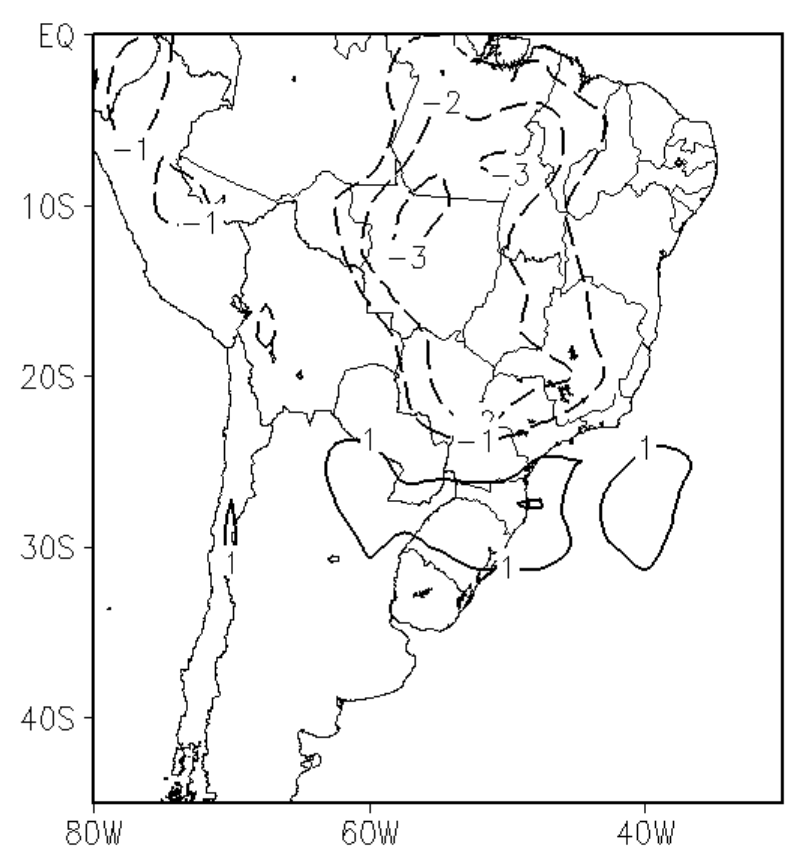

(c)

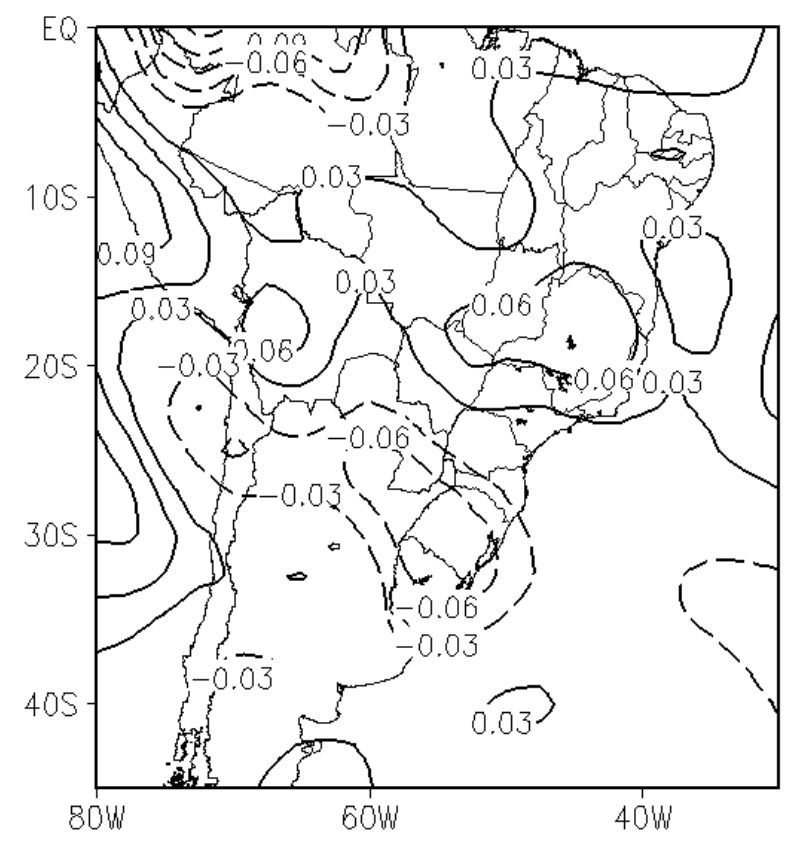

(d)

Fig. 5. Composite mean (a) surface temperature anomaly $\left({ }^{\circ} \mathrm{C}\right)$, (b) specific humidity anomaly $(\mathrm{g} / \mathrm{kg})$, (c) relative humidity anomaly $(\%)$, and (d) 500-hPa $\omega\left(\mathrm{Pa} \mathrm{s}^{-1}\right)$ for 17 strong WDSs during 1961-2003. 


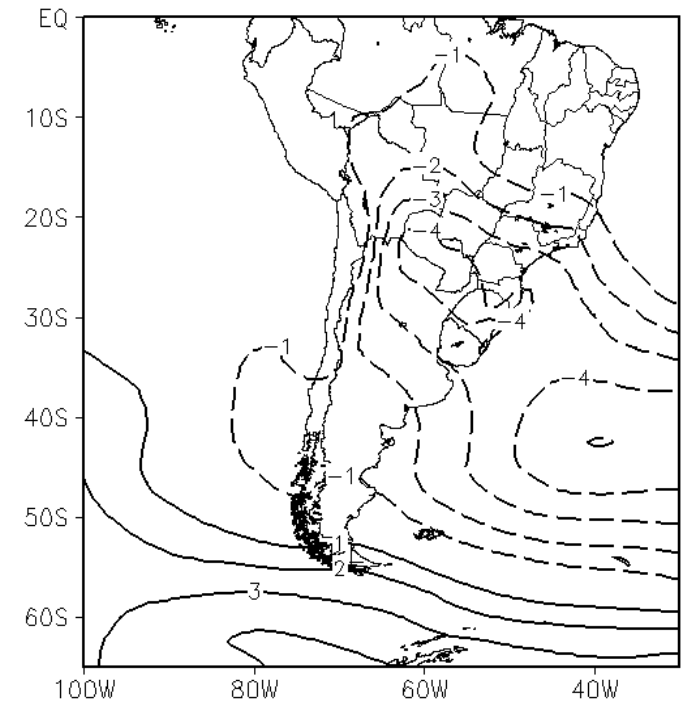

(a)

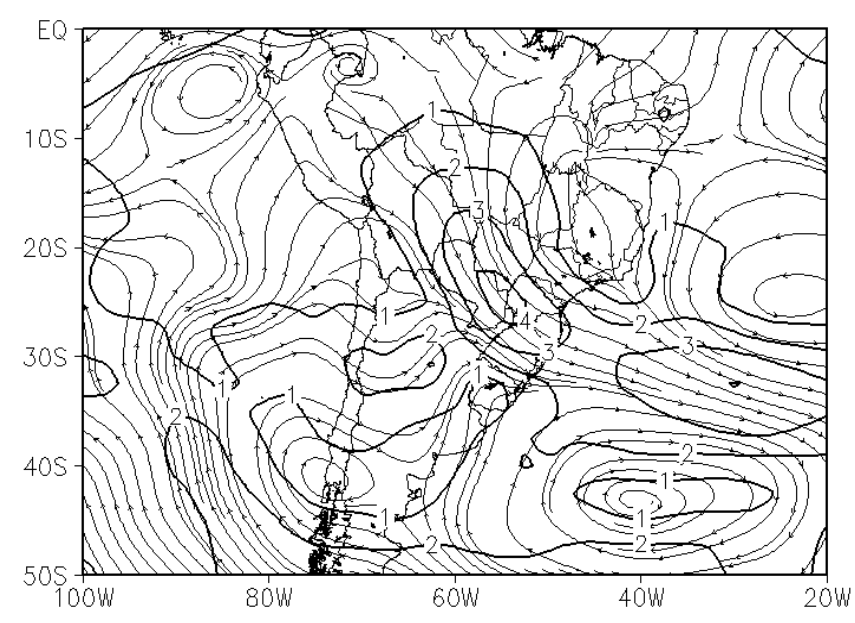

(c)

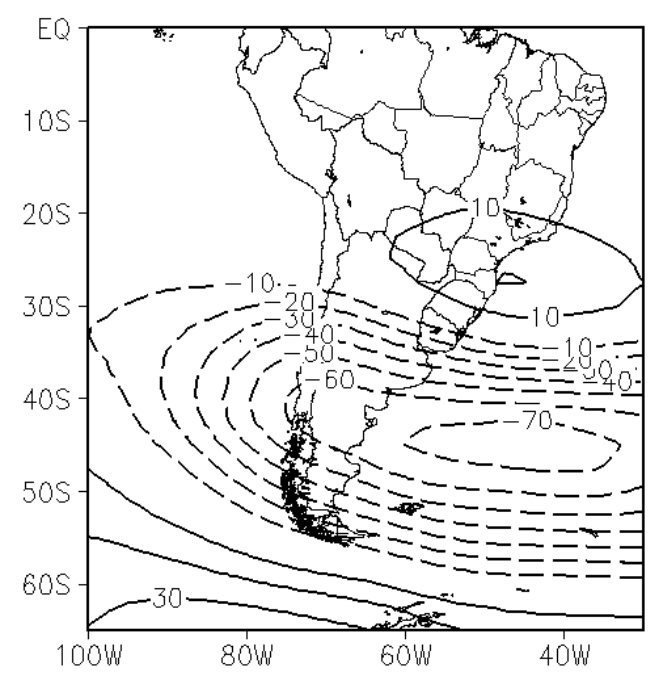

(b)

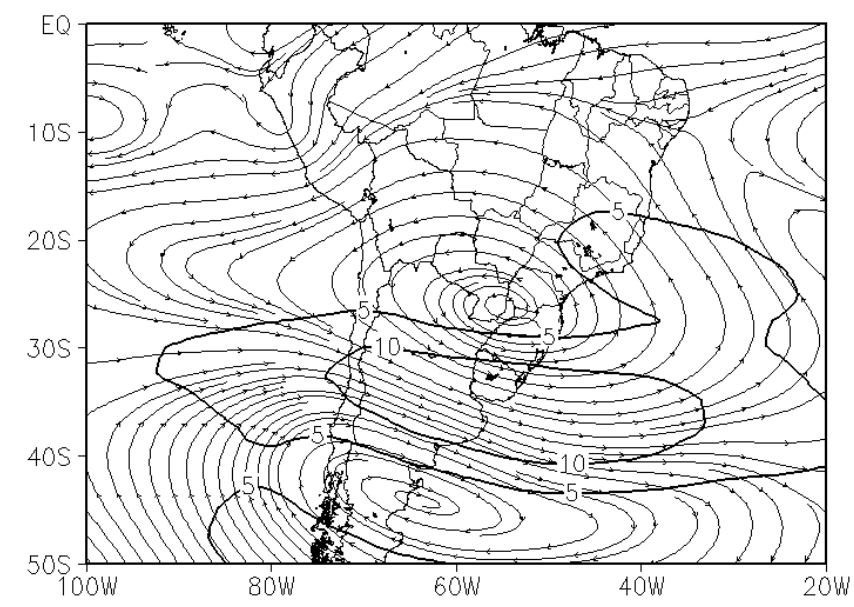

(d)

Fig. 6. Composite mean (a) surface pressure anomaly (hPa), (b) 500-hPa geopotential anomaly (m), (c) 850-hPa wind anomaly, and (d) 250-hPa wind anomaly for 17 strong WDSs. Dark lines in panels (c) and (d) are isotachs $\left(\mathrm{m} \mathrm{s}^{-1}\right)$ and light lines are streamlines.

this region the magnitude of the anomaly is greater than $5^{\circ} \mathrm{C}$. The specific humidity anomalies (Fig. 5c) are negative with values ranging from $-1 \mathrm{~g} / \mathrm{kg}$ to $-3 \mathrm{~g} / \mathrm{kg}$. The highest values of negative specific humidity anomalies are observed in central Brazil, north of the temperature anomaly maximum. The relative humidity anomalies (Fig. 5b) range from $-10 \%$ to $-25 \%$ over south-central Brazil. Higher temperatures and lower specific humidity values indicate that the subsidence of upper tropospheric air into the lower troposphere may also be playing an important role in warming and drying. To check this the 500-hPa $\omega$ is shown in Fig. 5d. There is widespread subsidence (positive values of $\omega$ ) over tropical South Amer- ica north of $20^{\circ} \mathrm{S}$ and ascending motion over northern Argentina and Uruguay. It is interesting to note that subsidence in the tropics and ascending motion to the south suggest circulation contrary to the Hadley circulation in the vertical plane.

The composites of the anomalies of sea-level pressure, 500-hPa geopotential, the $850-\mathrm{hPa}$ wind and $250-\mathrm{hPa}$ wind fields are given in Fig. 6. We note, firstly, a low pressure anomaly at sea level (Fig. 6a) and a high pressure anomaly at the 500-hPa level (Fig. 6b) over the south-central parts of Brazil. This is characteristic of a warmer-than-normal lower troposphere. The surface low pressure anomaly region is a 


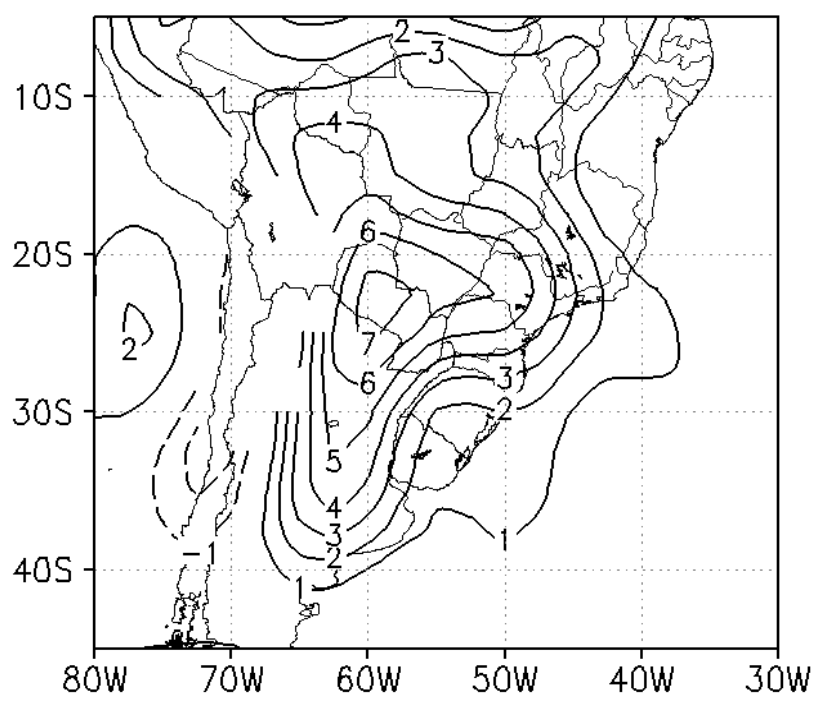

(a)

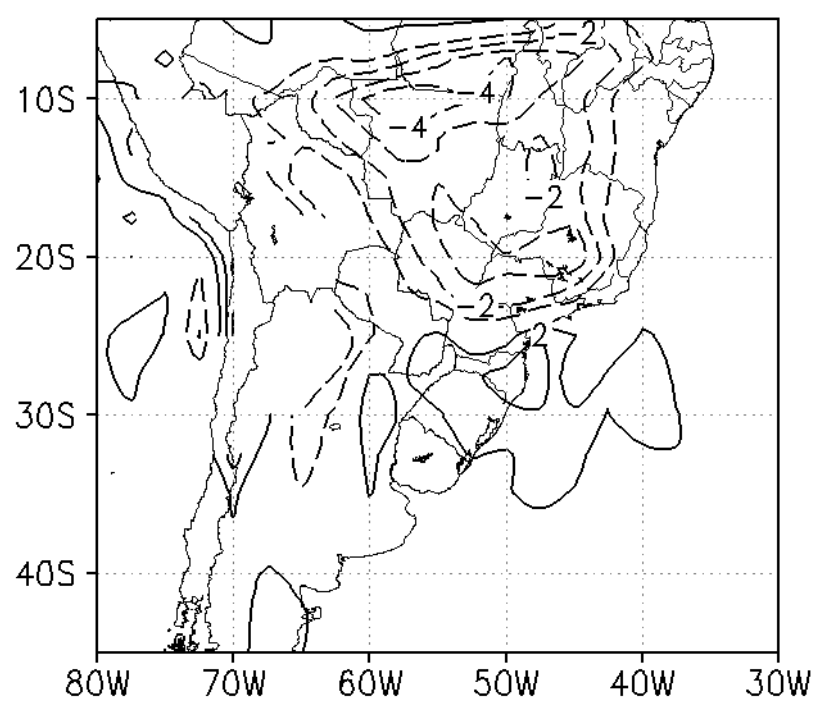

(c)

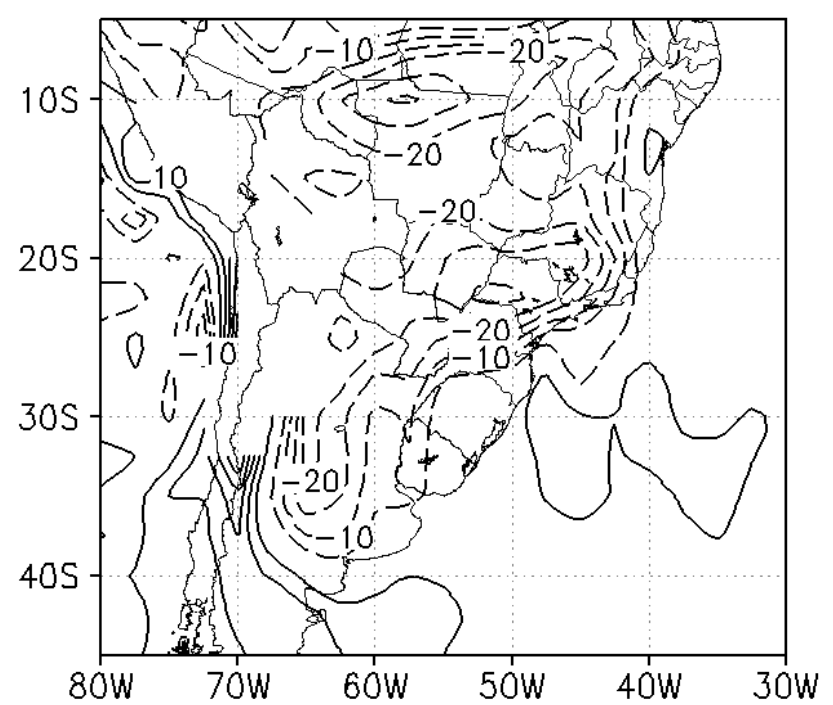

(b)

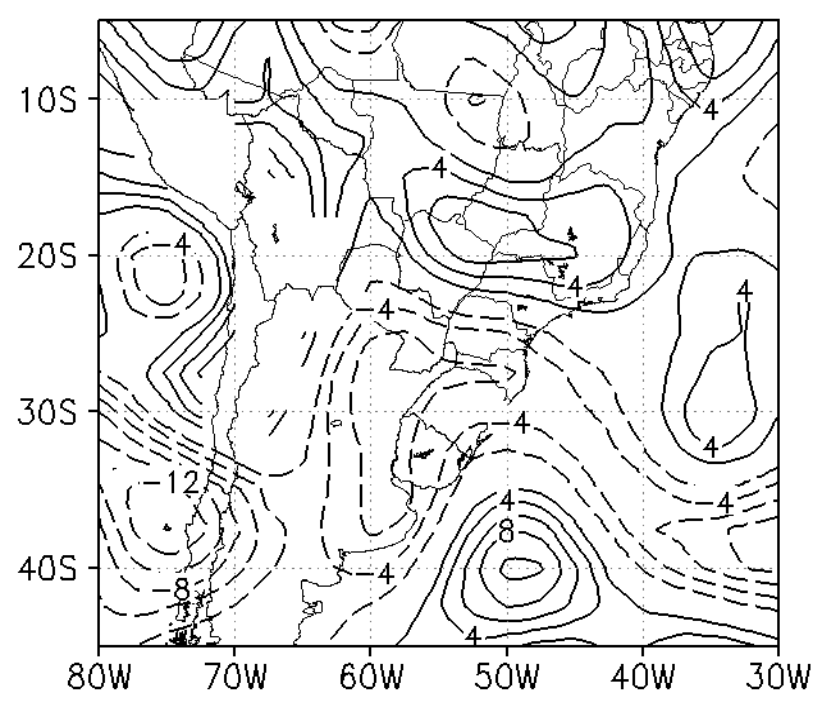

(d)

Fig. 7. Episode-mean anomaly fields for Case 29 (27 August through 10 September 1999) of (a) temperature ( $\left.{ }^{\circ} \mathrm{C}\right)$, (b) relative humidity (\%), and (c) specific humidity $\left(\mathrm{g} \mathrm{kg}^{-1}\right)$ at $1000 \mathrm{hPa}$ (surface), and (d) vertical velocity $\left(\mathrm{Pa} \mathrm{s}^{-1}\right)$ at 500 hPa, over South America at 00:00 UTC. Broken lines indicate negative values.

thermal low and the ridge or the high pressure region in the middle troposphere is a consequence of the hydrostatic balance. Actually, the whole field (not anomaly) of sea-level pressure (not presented) shows a closed low pressure center of $1008 \mathrm{hPa}$ over Paraguay.

The 850-hPa wind anomaly (Fig. 6c) shows a northwesterly component of more than $3 \mathrm{~ms}^{-1}$ over Paraguay and western Brazil. The whole field (not presented) shows a north-northwesterly wind maximum over Paraguay. These lower tropospheric northerlies confirm the circulation characteristics in the vertical plane mentioned above. The 250$\mathrm{hPa}$ wind anomaly (Fig. 6d) shows an anomalous anticyclonic circulation over the central parts of South America. The jetstream to the south of the circulation center is strengthened during the strong WDS episodes.

The lower pressure at the surface, ridge in the middle troposphere, anomalously strong northwesterlies in the lower troposphere and anticyclonic circulation in the upper 
troposphere are characteristics similar to summer circulation over South America, especially during the periods of activated South Atlantic Convergence Zone (SACZ) (Figueroa, 1997; Satyamurty et al., 1998), except that during SACZ events the upper level anticyclone is somewhat to the northwest of the anticyclonic anomaly shown in Fig. 6d, i.e. during the strong WDSs the atmospheric circulation acquires summer season characteristics in austral winter. There is of course one difference: there is no rainfall (or there is little rainfall) associated with WDS, whereas precipitation is generally heavy in the SACZ episodes.

\section{Horizontal and vertical structure, and the evolution of WDS}

The structure and evolution of WDS are presented for two cases: August-September 1999 (Case 29) and June 2002 (Case 32) WDS episodes. The episode mean characteristics over South America are shown first. These characteristics are different from the composite characteristics described in Sect. 3 in terms of the intensity of the anomalies and the position of the center of the WDS. Later, the evolution of the structure of the atmospheric flow during the WDS episodes is described. The reasons for choosing these two cases are that their intensities are distinct (see Table 1), one strong and the other moderate, and they happened during distinct phases of ENSO.

\subsection{August-September 1999 WDS}

The episode-mean anomaly fields of 1000-hPa temperature, relative humidity, specific humidity and 500-hPa vertical motion, $\bar{T}, \bar{r}, \bar{q}$ and $\bar{\omega}$, respectively, over South America for the Aug-Sep 1999 WDS (Case 29 in Table 1) are shown in Fig. 7. The positive temperature anomaly and negative relative humidity anomaly centers at about $24^{\circ} \mathrm{S}, 59^{\circ} \mathrm{W}$ occupy large areas in Brazil and adjoining countries, mainly Argentina, Paraguay and Bolivia (Figs. 7a and b). The 14-day mean temperature is $7{ }^{\circ} \mathrm{C}$ higher than normal and the relative humidity is $25 \%$ lower than the climatology in the centers of the respective fields. The horizontal extent of the area affected by the WDS is very large. The WDS is a continental size phenomenon. Figure 7 shows the full intensity of a single episode while Fig. 5 shows the average of 17 episodes.

The specific humidity anomaly (Fig. 7c) is negative north of $25^{\circ} \mathrm{S}$, with a magnitude of $\sim 2 \mathrm{~g} \mathrm{~kg}^{-1}$ in the subtropical region and $\sim 4 \mathrm{~g} \mathrm{~kg}^{-1}$ in the tropical region over the eastern Amazon Basin in Brazil. This indicates that, during this WDS, the relative humidity anomaly is strongly affected by lower water vapor content in the air (Fig. 7c), as well as by the higher temperature (Fig. 7a).

The mean vertical velocity field at $500 \mathrm{hPa}$ (Fig. 7d) shows that the vertical motion is largely subsidence over the subtropical Brazil. Subsidence in the middle troposphere causes the air to become warmer by adiabatic compression and drier by downward advection of upper tropospheric air into the lower troposphere. Strong rising motion is found south of $22^{\circ} \mathrm{S}$ in northeastern Argentina and southern Brazil. In these regions the thermal advection should have an important role for the appearance of positive temperature anomalies during the WDS.

In order to obtain an idea of the depth of the warm and dry air mass during the WDS, episode-mean fields of temperature, relative humidity and specific humidity anomalies are also calculated at $850 \mathrm{hPa}$ and $700 \mathrm{hPa}$. Figure 8 shows the fields at $850 \mathrm{hPa}$ for this WDS case. The centers of the positive temperature anomaly and the negative relative humidity anomaly occupy large areas over the South American continent north of $40^{\circ} \mathrm{S}$. The anomaly centers are somewhat weaker at this level and are shifted to the east compared to the surface anomalies. The negative anomalies of specific humidity (Fig. 8c) are of the order of $1 \mathrm{~g} \mathrm{~kg}^{-1}$ in the subtropics and tropics over the continent. These anomalies in the three fields persist up to the 700-hPa level (figure not shown) but with reduced intensity. On the whole, the observations show that the warm and dry air mass responsible for the WDS is fairly deep, occupying the whole lower troposphere.

A sequence of the fields of 500-hPa geopotential height and its anomaly for the period 24 August through 9 September 1999 at intervals of two to five days is shown in Fig. 9. The sequence starts with a positive geopotential anomaly over Argentina on 24 August (Fig. 9a, two days before the beginning of WDS) and ends with a large negative anomaly on 9 September (Fig. 9f) towards the end of the WDS. Over the South Pacific Ocean the conditions observed are: (1) geopotential anomalies of opposite signs, on the average, north of $40^{\circ} \mathrm{S}$ and south of $45^{\circ} \mathrm{S}$, (2) a strong ridge around $120^{\circ} \mathrm{W}$ and a strong trough downstream in the period 24-28 August, considered the development stage of the WDS, (3) a blocking-like situation near $90^{\circ} \mathrm{W}$, with a low center around $45^{\circ} \mathrm{S}$ and a ridge to the south, in the period 31 August3 September, (4) a strong ridge at $100^{\circ} \mathrm{W}$ flanked by deep troughs on 7 September moving to $90^{\circ} \mathrm{W}$ on 9 September. A highly amplified trough formation over Argentina, Paraguay and southern Brazil on 9 September indicates cooler air in the lower troposphere which slowly moves northeastward, causing the temperatures to cool down over the central parts of the continent in the subsequent days.

The sequence described resembles somewhat a dipole omega block (Lejenas, 1984) in the first half of the WDS. The negative anomalies to the north and the positive anomalies to the south of $45^{\circ} \mathrm{S}$ (Fig. 9d) reduce the south-to-north pressure gradient in the eastern South Pacific. This, in turn, reduces the strength of the westerly current in the Pacific. This causes the weather systems over South America to advance slowly. Moreover, the dry air mass over the continent does not permit the weather systems to penetrate northward. The short wave low-pressure center over Chile at $32^{\circ} \mathrm{S}$ on 24 August moves to $40^{\circ} \mathrm{S}, 65^{\circ} \mathrm{W}$ in the Atlantic on 26 August. 


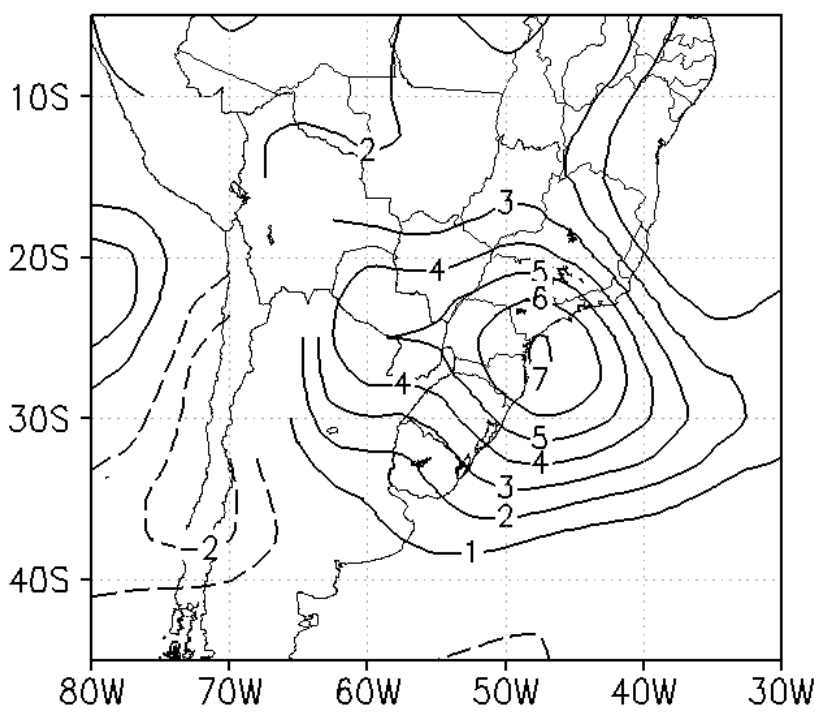

(a)

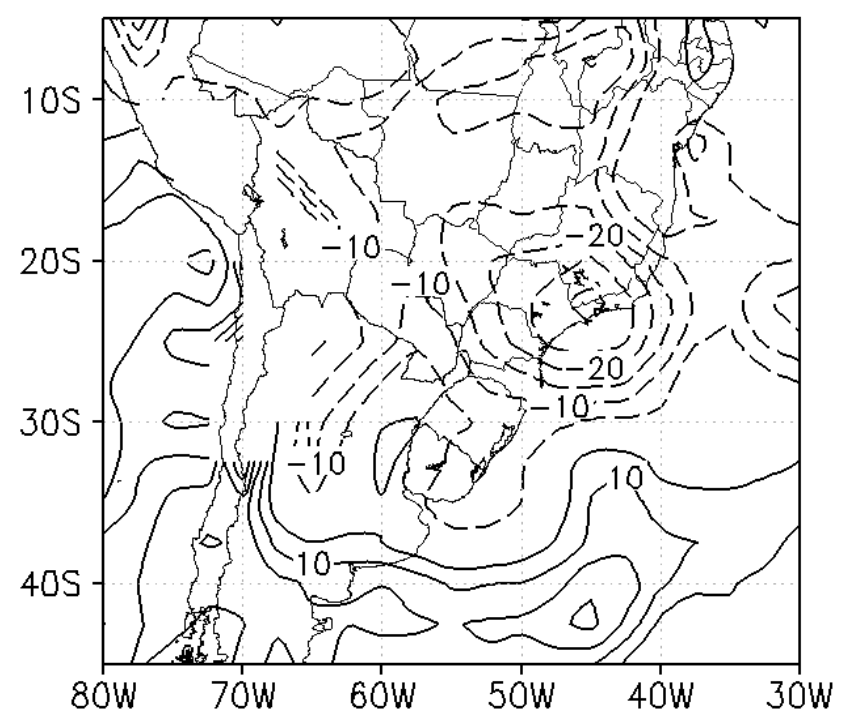

(b)

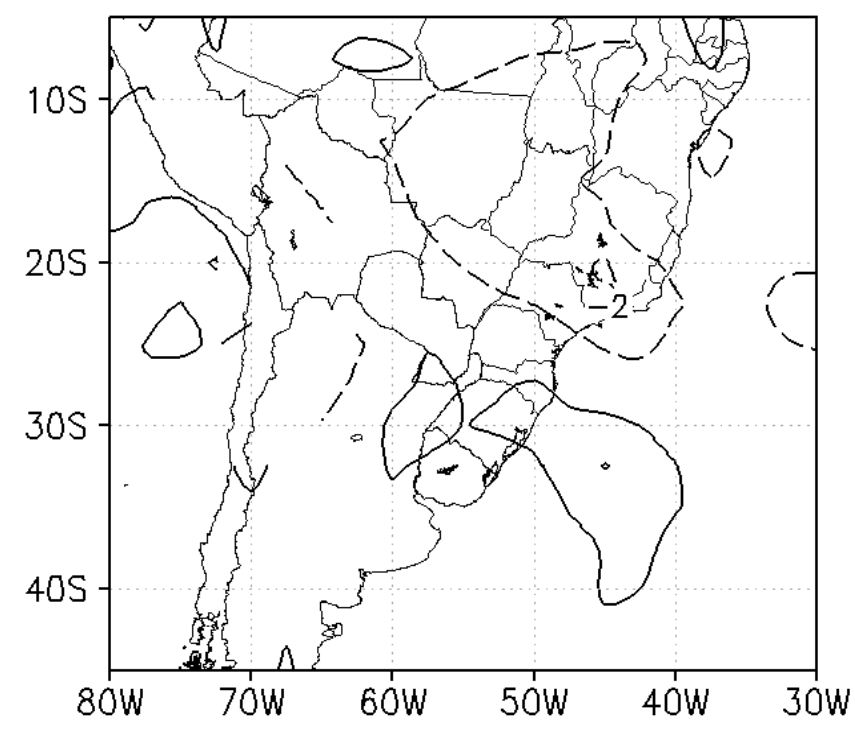

(c)

Fig. 8. Episode-mean anomaly fields for Case 29 (27 August through 10 September 1999) of (a) temperature ( $\left.{ }^{\circ} \mathrm{C}\right)$, (b) relative humidity $(\%)$, and (c) specific humidity $\left(\mathrm{g} \mathrm{kg}^{-1}\right)$ at $850 \mathrm{hPa}$. Broken lines indicate negative values.

However, the low center in the Pacific at $90^{\circ} \mathrm{W}, 47^{\circ} \mathrm{S}$ on 31 August stays unmoved till 3 September (Fig. 9d). Only on 7 September does it become a trough and starts moving eastward on to the continent. On 9 September the trough intensifies over the continent (Fig. 9f). The intensification and movement of this trough has implications regarding the movement of a frontal system at the surface, which we will see in the surface pressure fields given in Fig. 10.

The sequence of sea-level pressure also shows the same characteristics seen in the middle troposphere in the eastern
South Pacific, namely, largely negative anomalies north of $45^{\circ} \mathrm{S}$ and positive anomalies to the south, with situations resembling a blocking. From 26 August through 3 September (Figs. 10b-d) a high-pressure center around $60^{\circ} \mathrm{S}$ and a lowpressure center to its north are shown around $100^{\circ} \mathrm{W}$. From 26 through 31 August the South Atlantic subtropical high somewhat approaches the continent, and a low-pressure center deepens in northern Argentina on 31 August. As a result, a strong west-to-east pressure gradient builds which permits strong northerlies over central and southern Brazil, which, in 


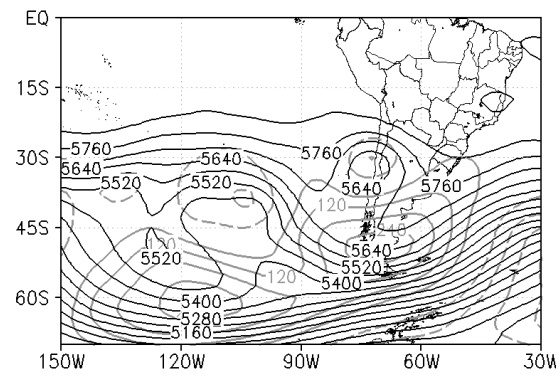

(a)

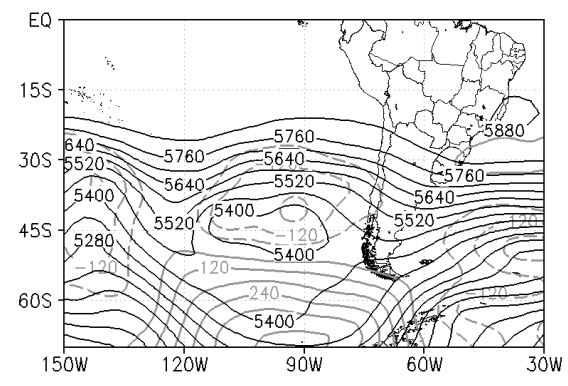

(d)

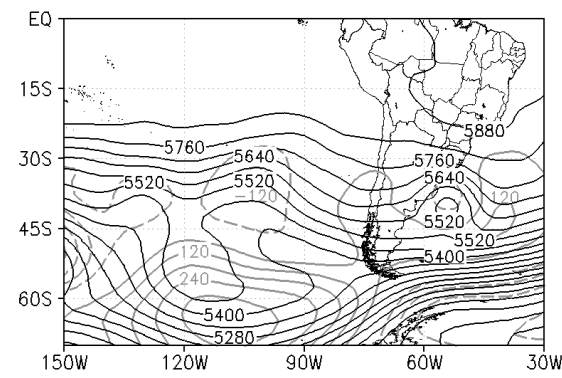

(b)

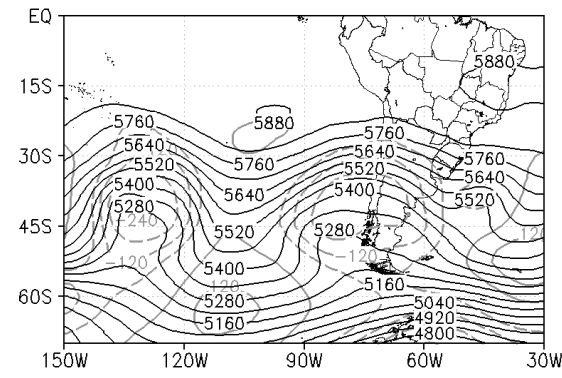

(e)

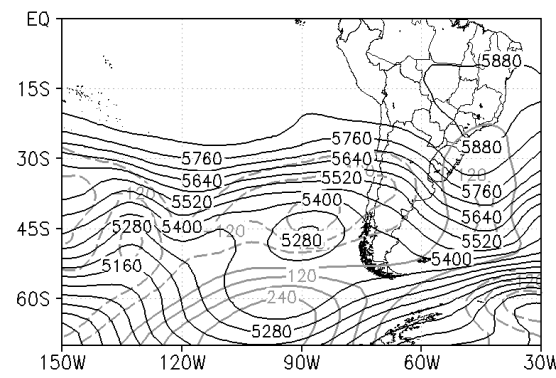

(c)

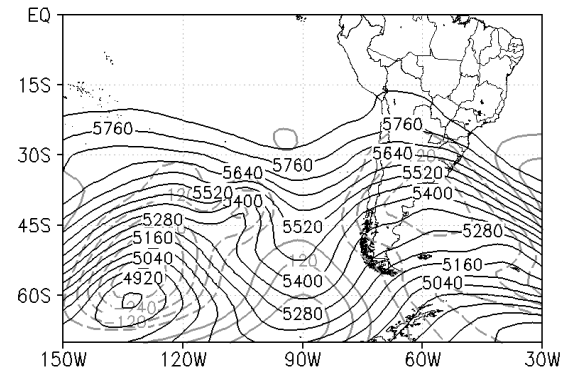

(f)

Fig. 9. 500-hPa geopotential height (m) and its anomaly for (a) 24, (b) 26, (c) 31 August, (d) 3, (e) 7, (f) 9 September 1999 at 00:00 UTC. Darker lines are geopotential and lighter lines are anomalies. Broken lines indicate negative anomalies.

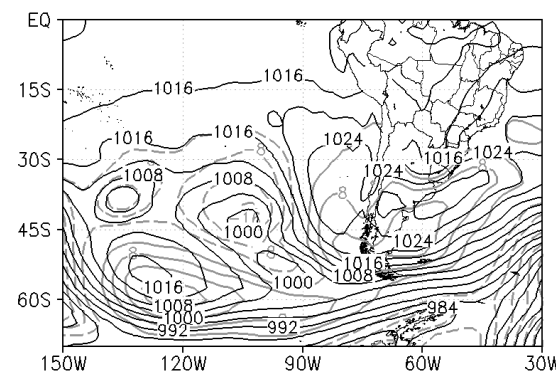

(a)

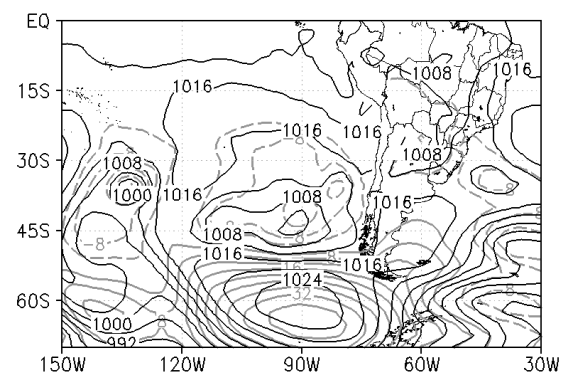

(d)

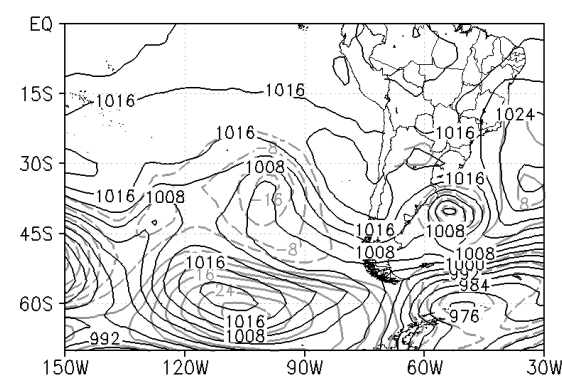

(b)

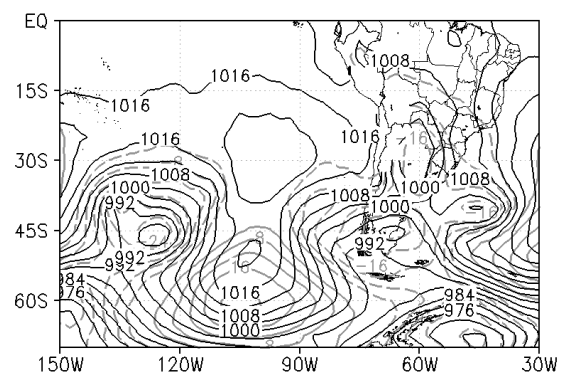

(e)

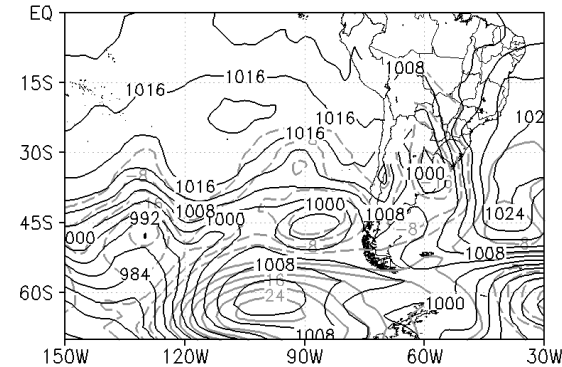

(c)

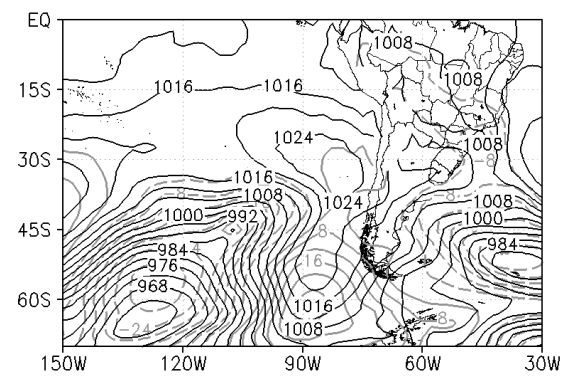

(f)

Fig. 10. Same as in Fig. 8 except for the mean sea-level pressure (hPa).

turn, permits strong thermal advection. The near north-south orientation of the isobars in Brazil continues up to 7 September. The winds at $850 \mathrm{hPa}$ on 31 August, 3 September and 7 September, shown in Fig. 11, give us an idea of the persistence of the northerly flow in the lower troposphere.
A low-pressure center in the Atlantic off the Argentina coast intensifies on 7 September (not shown), as a consequence of the warm advection at the surface and is helped by the approaching middle tropospheric trough described in the last paragraph. A surface frontal boundary, connecting 


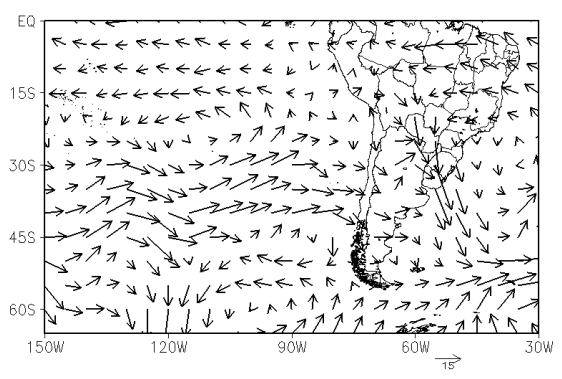

(a)

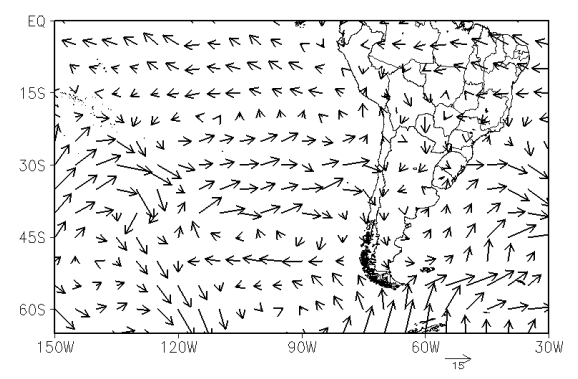

(b)

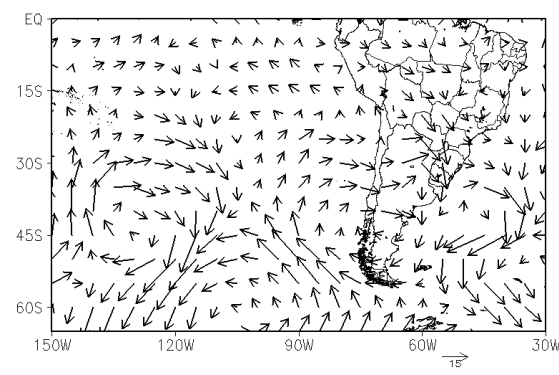

(c)

Fig. 11. 850-hPa flow field for (a) 31 August, (b) 3, (c) 7 September 1999 at 00:00 UTC.

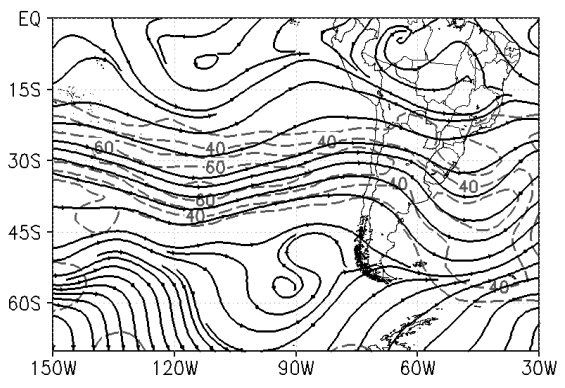

(a)

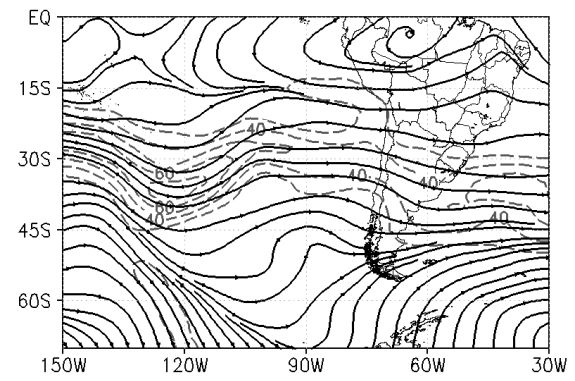

(b)

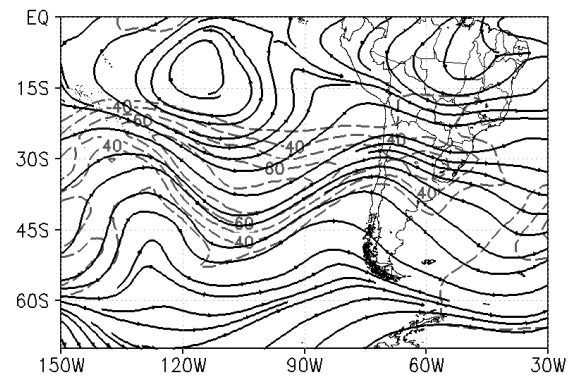

(c)

Fig. 12. 200-hPa flow field for (a) 31 August, (b) 3, (c) 7 September 1999 at 00:00 UTC. Darker lines are streamlines and lighter lines are isotachs, drawn at intervals of $20 \mathrm{~m} \mathrm{~s}^{-1}$ starting from $30 \mathrm{~m} \mathrm{~s}^{-1}$.

the low center with the low-pressure area over northern Argentina can be drawn. To the west of the low-pressure center strong, cold advection occurs over Argentina on 8 September (figure not shown). This cold advection area over Argentina and the warm advection area over Brazil define the frontal boundary, which moves into central Brazil on 9 September (Fig. 10f). The progression of this frontal system into central Brazil is responsible for the dissipation of the WDS.

Figure 12 shows the 200-hPa flow field on the same days as in Fig. 11. One striking feature is the anticyclonic circulation north of $20^{\circ} \mathrm{S}$ over the Amazon region and a trough downstream. This is a situation similar to the Bolivian High and the Northeast Cyclone observed during summer (Satyamurty et al., 1998), i.e. the upper tropospheric circulation in midwinter acquires summer season characteristics during the WDS. The anticyclonic vorticity north of the jetstreak over the central parts of Brazil (both shear vorticity and curvature vorticity are anticyclonic) is an indication of the anomalous warm conditions in the lower troposphere.

\subsection{June 2002 WDS}

Figure 13 shows the episode-mean (2-11 June 2002) anomalies of temperature, relative humidity, specific humidity and vertical motion for the WDS. The warm anomalies are seen mainly over Brazil centered at $20^{\circ} \mathrm{S}, 52^{\circ} \mathrm{W}$. Except for the northern Amazon region and the eastern coast of Northeast Brazil, the whole country is under a warm spell. The maximum episode-mean warm anomaly is $5^{\circ} \mathrm{C}$. Compared to Case 29 the core of this WDS is shifted northward and is less intense in terms of the temperature anomaly. This case is classified as a moderate event for two reasons. One is its shorter duration compared with Case 29 and the other is that the positive temperature anomaly core is only approximately $5^{\circ} \mathrm{C}$. The relative humidity anomalies (Fig. 13b) of the order of $20 \%$ over Brazil occupy tropical and subtropical regions north of $25^{\circ} \mathrm{S}$. By examining Fig. 13c we find that, although the air was more humid than normal in southern and northwestern Brazil, the anomalies over Brazil east of $60^{\circ} \mathrm{W}$ and north of $20^{\circ} \mathrm{S}$ are negative with magnitudes of the order of $2 \mathrm{~g} \mathrm{~kg}^{-1}$. (The negative anomalies in both humidity parameters over western Argentina are probably due to the incursion of a cold (polar) air mass.) Similar temperature and humidity characteristics are observed at 850 - and 700 -hPa levels (figures not shown). The vertical motion in the middle troposphere (Fig. 13d) shows subsidence between $10^{\circ} \mathrm{S}$ and $20^{\circ} \mathrm{S}$ of the order of $8 \mathrm{~Pa} \mathrm{~s}^{-1}$. However, strong ascending motion dominates south of $20^{\circ} \mathrm{S}$ over northern Argentina and southern Brazil. These fields indicate that, in the $10^{\circ} \mathrm{S}-20^{\circ} \mathrm{S}$ latitude belt, the subsidence plays an important role in raising the temperatures and drying the atmosphere in the lower troposphere. 


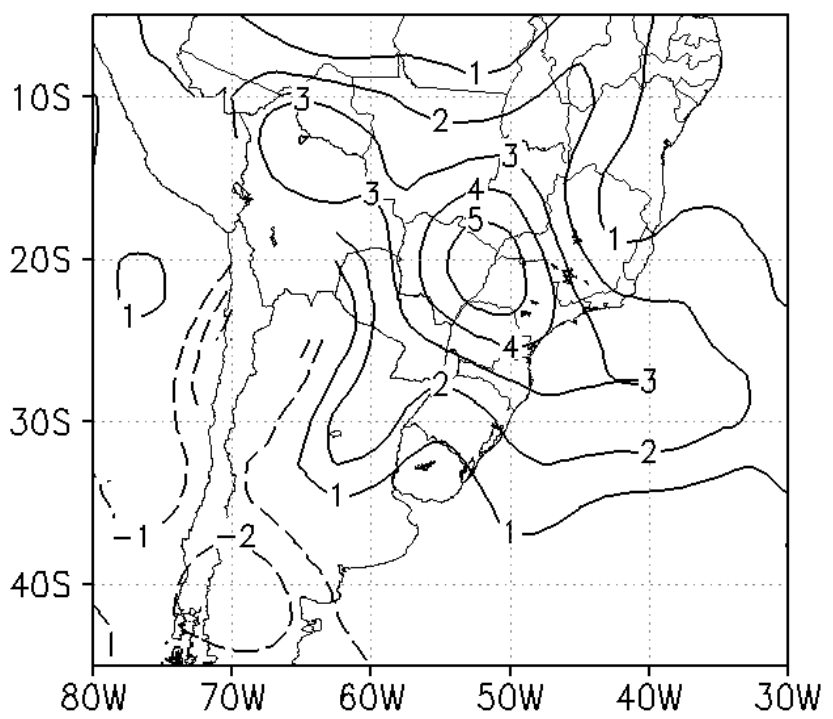

(a)

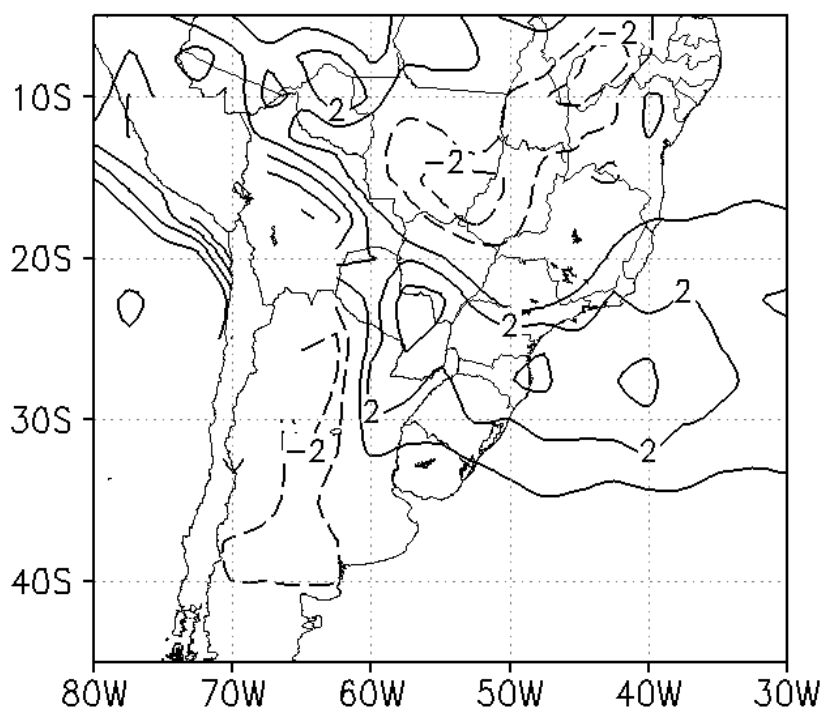

(c)

Fig. 13. Same as in Fig. 5 except for Case 32 (2-11 June 2002).

The sequence of the 500-hPa geopotential and its anomaly from 29 May through 12 June 2002 (not shown) shows a strong ridge propagating slowly from $130^{\circ} \mathrm{W}$ to $110^{\circ} \mathrm{W}$ in the Pacific in 8 days from 29 May to 5 June. From 5 to 8 June a strong trough has formed north of $47^{\circ} \mathrm{S}$ and, along with the ridge to the south, the geopotential field resembles an inverted omega blocking configuration. On 12 June the ridge moves to $90^{\circ} \mathrm{W}$. The short wave trough off Chile at $30^{\circ} \mathrm{S}$ remains stationary in the eastern South Pacific till it
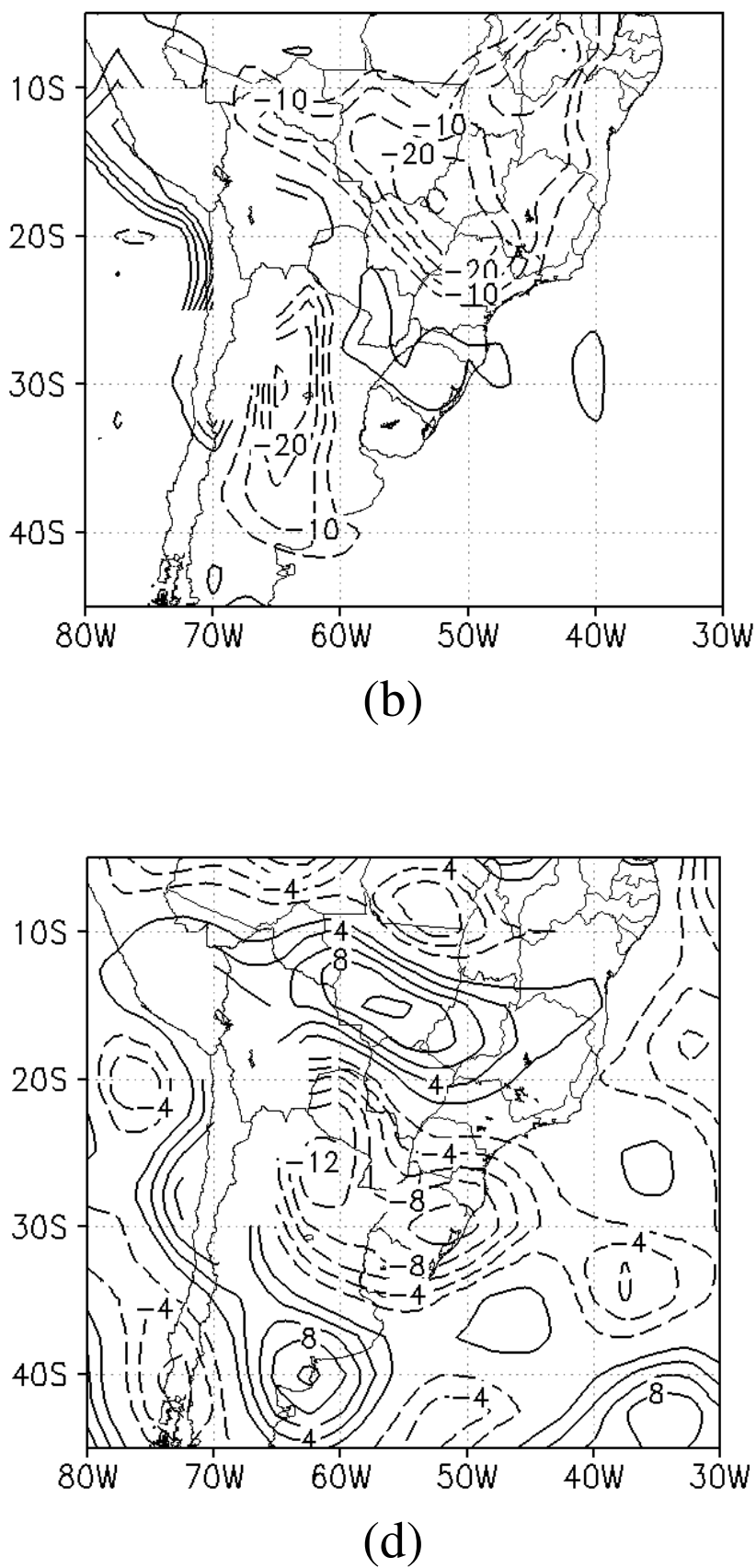

crosses the Andes on 10 June and moves on to the continent and later on to the Atlantic Ocean. The northward incursion of the frontal boundary associated with this trough has contributed for the dissipation of the WDS after 12 June.

The sea-level-pressure and its anomaly sequences (not shown) also show some blocking-like characteristics in the Pacific. In this case, a surface front remains stationary over Uruguay, Paraguay and northern Argentina from 2 through 7 June. During this period the temperatures over Brazil rise 


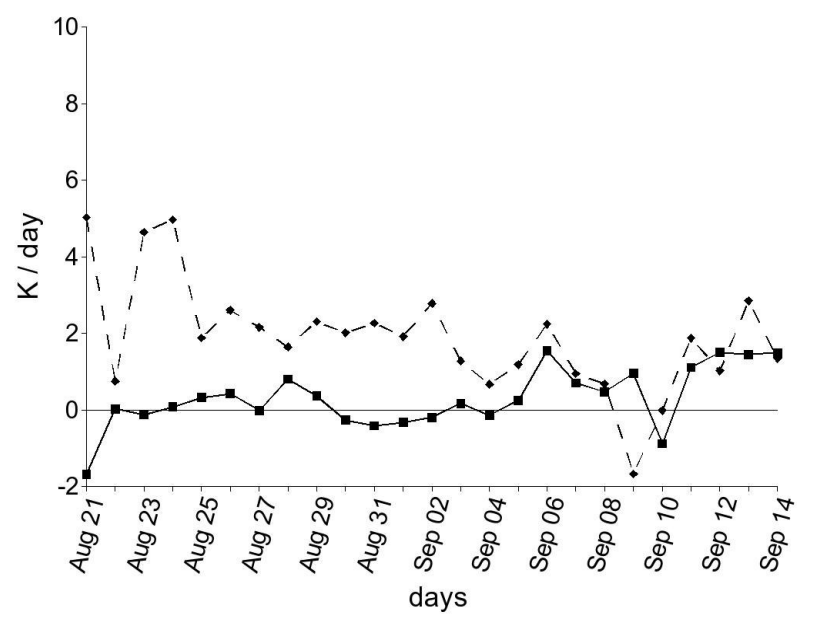

(a)

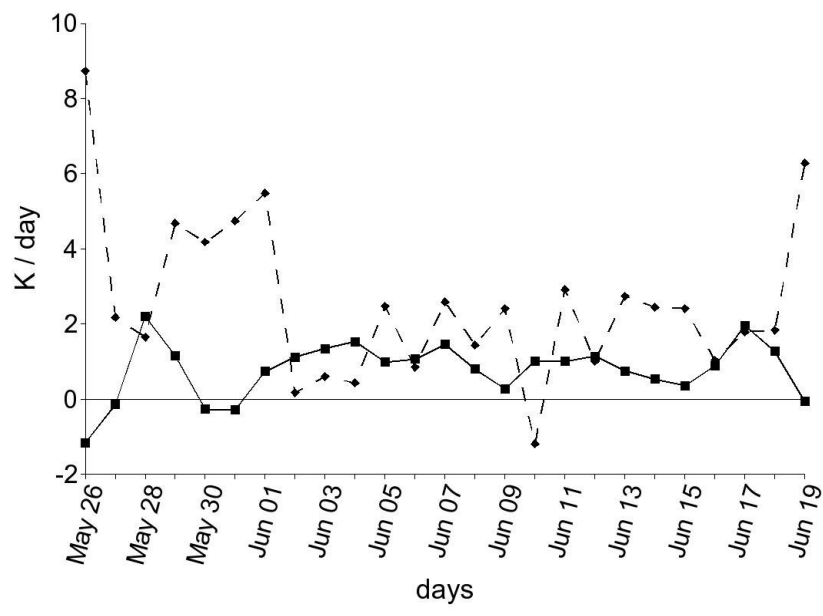

(b)

Fig. 14. Evolution of target-area average horizontal thermal advection (full lines) and adiabatic heating (broken lines) $\left(\mathrm{K} \mathrm{day}^{-1}\right)$ at 700-hPa for (a) Case 29 and (b) Case 32.

and remain high. Between 12 and 15 June another frontal boundary moves northeastward, with the penetration of a high-pressure cell over Argentina. This progression of the frontal boundary into the subtropics of Brazil is responsible for the dissipation of the WDS, as is mentioned in the last paragraph.

The 200-hPa streamlines (not shown) show the formation of an anticyclonic circulation center over the Amazon region around $10^{\circ} \mathrm{S}$ with a trough downstream over the coast of northeast Brazil. Once again the situation resembles summer circulation over the region. The anticyclone and the ridge at $200 \mathrm{hPa}$ over the central parts of Brazil indicate a warm lower troposphere. Towards the end of WDS the anticyclonic center moves eastward on to northeast Brazil.
There are some differences between the two cases presented but essentially they show the same characteristics. A warm and dry air mass occupies a large area over the continent. The subsidence motion in the middle troposphere seems to have an important role in the drying and warming of the lower tropospheric air in the tropical regions of Brazil. A slow moving strong ridge over the South Pacific shows some blocking like characteristics. The progression of a frontal boundary associated with a midtropospheric trough into Brazil is responsible for the dissipation of the WDSs. The differences are mainly seen in the intensity of the thermal anomaly and the horizontal extension of the warm and dry airmass. Case 32 is weaker than Case 29 and the difference in intensities of the two events is well indicated by SI (Table 1). The qualitative similarity of all major characteristics of the two events described above suggests that these phenomena are not significantly influenced by the ENSO phase.

\section{Diagnostics for the temperature and humidity anoma- lies and changes}

Besides the diabatic heating due to the liberation of latent heat, if any, and the short- and long-wave radiation, there are basically two mechanisms by which the temperature can change from a near normal situation (prior to WDS) to a WDS situation. They are the horizontal thermal advection and adiabatic heating due to vertical motion. Similarly, in the case of the changes in specific humidity, the mechanisms are the horizontal and vertical advections of humidity, besides precipitation, if any, and evaporation. The horizontal and vertical advections of temperature and humidity are calculated at 850- and 700-hPa and are considered to be representative of the role played by the lower tropospheric winds and vertical motions in the changes in temperature and humidity associated with WDS. The results of these calculations for the two cases of WDS presented in Sect. 4 are discussed here.

The mean fields during the five days around the first day of the WDS episode are found to be useful for explaining the evolution from pre-WDS to WDS situations. This period may be considered as the development stage of the WDS (24-28 August 1999 in Case 29 and 31 May-4 June 2002 in Case 32). It should be mentioned that the calculations of horizontal and vertical thermal and humidity advections made using the $1000-\mathrm{hPa}$ and $925-\mathrm{hPa}$ data showed many "bullseye" patterns, perhaps due to the effect of steep Andean topography and smaller magnitudes of vertical motion, and are therefore not presented.

The evolution of the target-area averages of the horizontal thermal advection and adiabatic heating due to vertical motion at $700 \mathrm{hPa}$ during the two WDS are plotted in Fig. 14. While both terms are generally positive on most of the days of the events and prior to the events, it is very clear from the figure that the role of subsidence was more expressive 


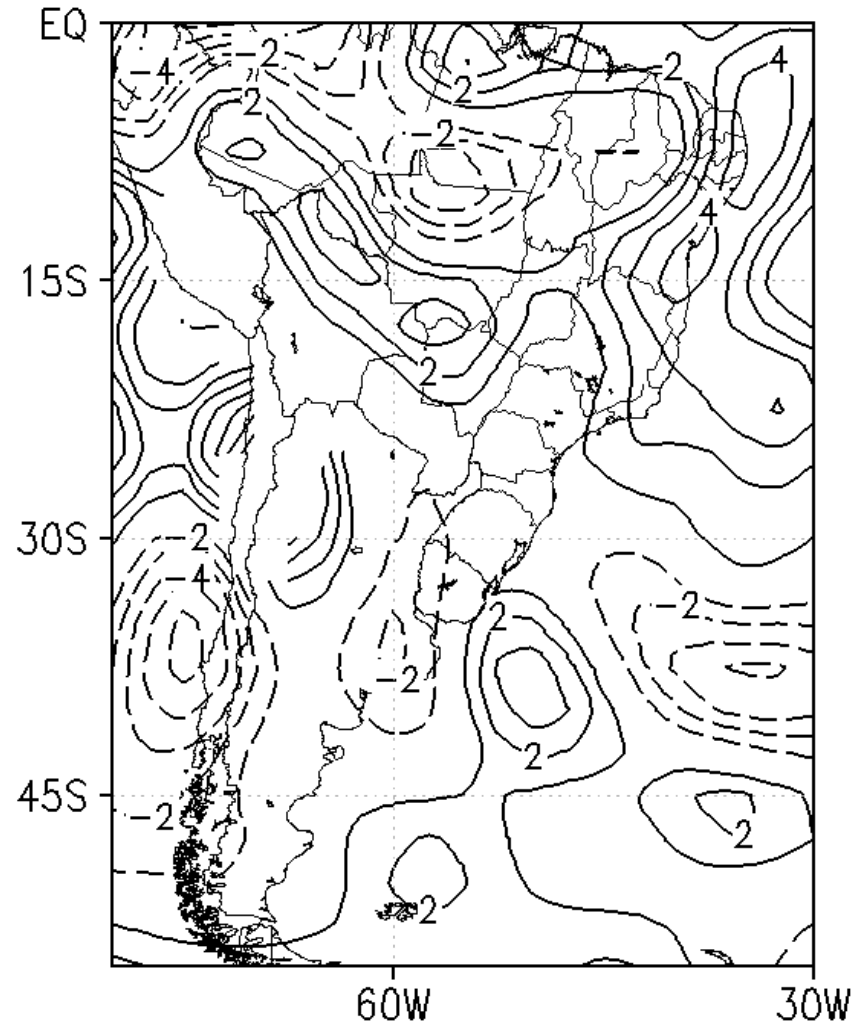

(a)

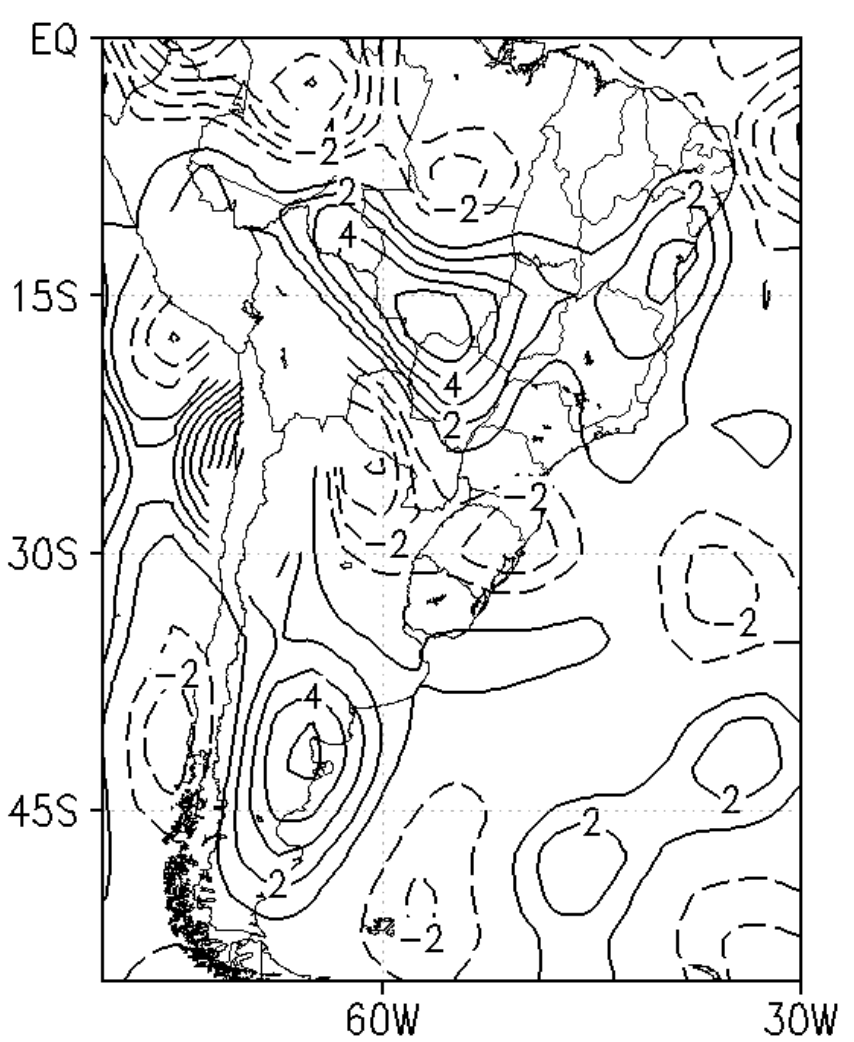

(b)

Fig. 15. Episode-mean fields of adiabatic heating due to vertical motions ( $\mathrm{K} \mathrm{day}^{-1}$ ) at $700 \mathrm{hPa}$. (a) Case 29 , and (b) Case 32 .

compared to the horizontal advection. The dominance of the effects of subsidence over the target area is more evident in the beginning of the episodes or in the development stages, 23-26 August 1999 (Case 29) and 29 May-1 June 2002 (Case 32). The episode-mean adiabatic heating due to vertical motions at $700 \mathrm{hPa}$ for the two cases is shown in Fig. 15. In both cases of WDS strong warming is observed over the subtropics of Brazil, of the order of 3 to $4 \mathrm{~K} \mathrm{day}^{-1}$, once again showing the important role played by the regional scale subsidence in the maintenance of the WDS.

Five-day average fields of vertical advection of specific humidity, $-\omega(\partial q / \partial p)$, during the development stage of the WDS, at 850 and $700 \mathrm{hPa}$, for Cases 29 and 32, are shown in Fig. 16. North of $30^{\circ} \mathrm{S}$ the vertical advection is mostly negative, of the order of $1 \mathrm{~g} \mathrm{~kg}^{-1} \mathrm{day}^{-1}$ in Case 29 and $2 \mathrm{~g} \mathrm{~kg}^{-1}$ day $^{-1}$ in Case 32, at both levels. These results show that the regional scale subsidence has played an important role in the drying of the lower tropospheric air during the development stage of the WDS. The wetting effect in southern Paraguay and northeastern Argentina in Case 32 was due to rising motion associated with frontal systems, which did not propagate into Brazil. Figure 17 shows the horizontal advection of specific humidity in the development stage. The effect is also mostly drying over the continent.
The episode-mean fields of vertical and horizontal advections of water vapor in the lower troposphere (at 850 and $700 \mathrm{hPa}$ ) are, respectively, shown in Figs. 18 and 19, for both cases. In general, the effects of advections by vertical motions and horizontal motions are drying in both cases of WDS. However, in the central parts of Brazil the drying due to vertical advection (i.e. due to subsidence) is larger than that due to horizontal advections.

Figure 20 shows the composite fields of horizontal and vertical advections of temperature at the $850 \mathrm{hPa}$ level for the 17 strong WDSs. Once again, it can be seen that both the processes contribute to the rise of temperature in the central parts of Brazil and adjoining regions in Paraguay, Uruguay and Argentina. The importance of vertical advection, i.e. subsidence of upper tropospheric air, is of the same order or stronger than the horizontal advection.

\section{Summary and conclusions}

In this study, for the first time, the warm and dry episodes in the central parts of South America in the winter and postwinter months are described qualitatively and quantitatively. Although the target area considered in this study is smaller 


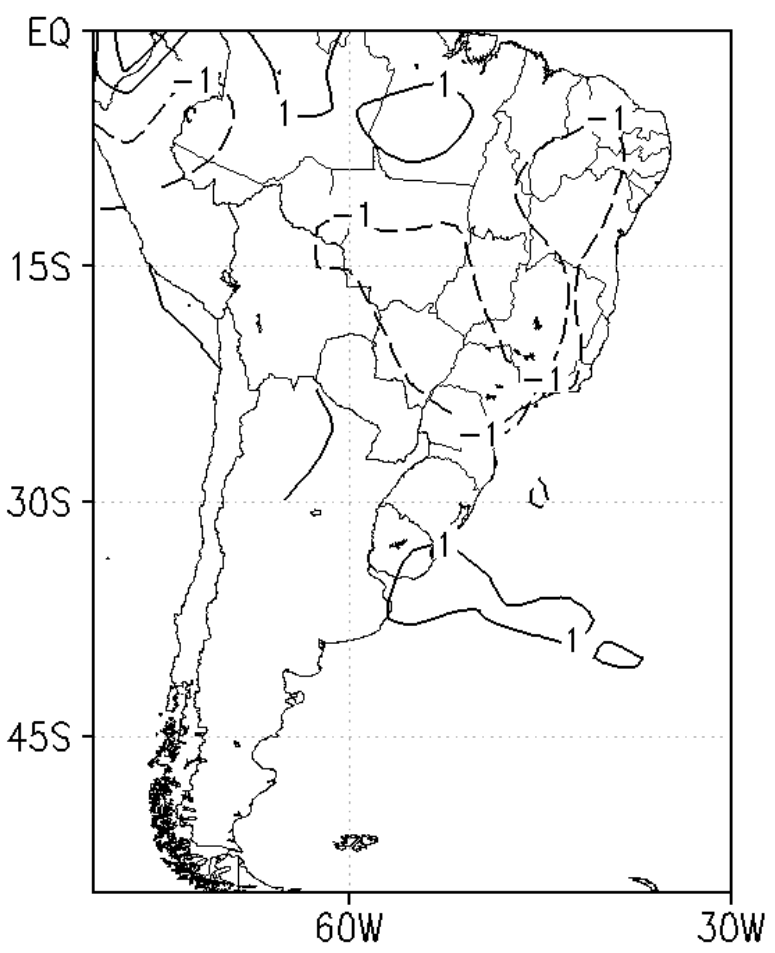

(a)

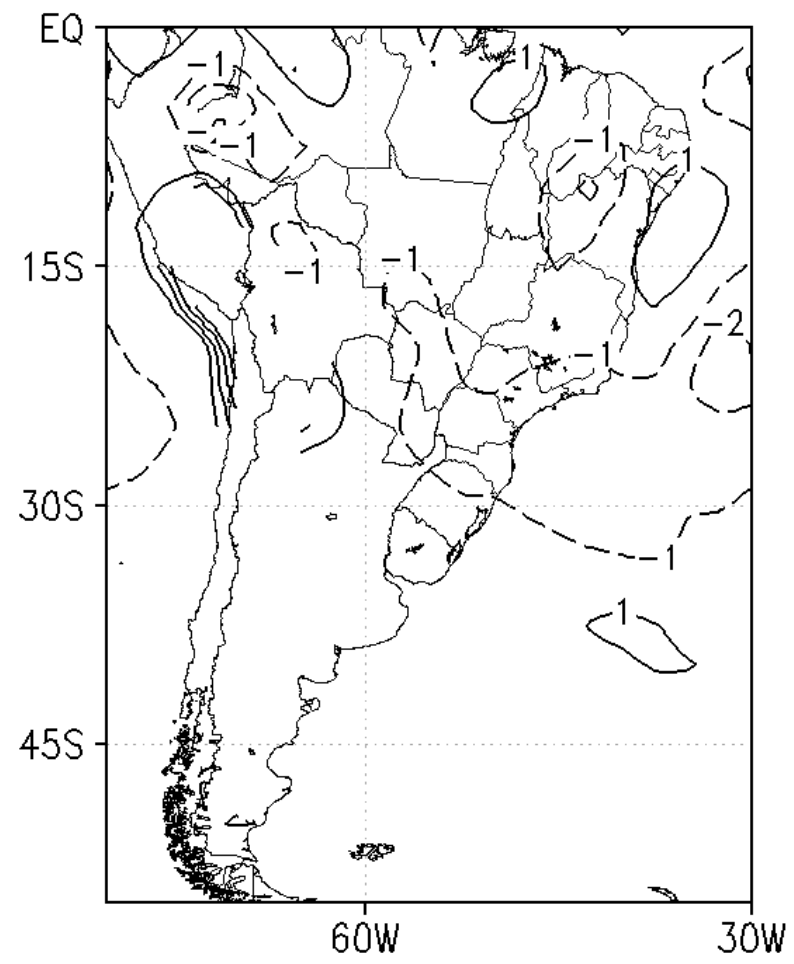

(c)

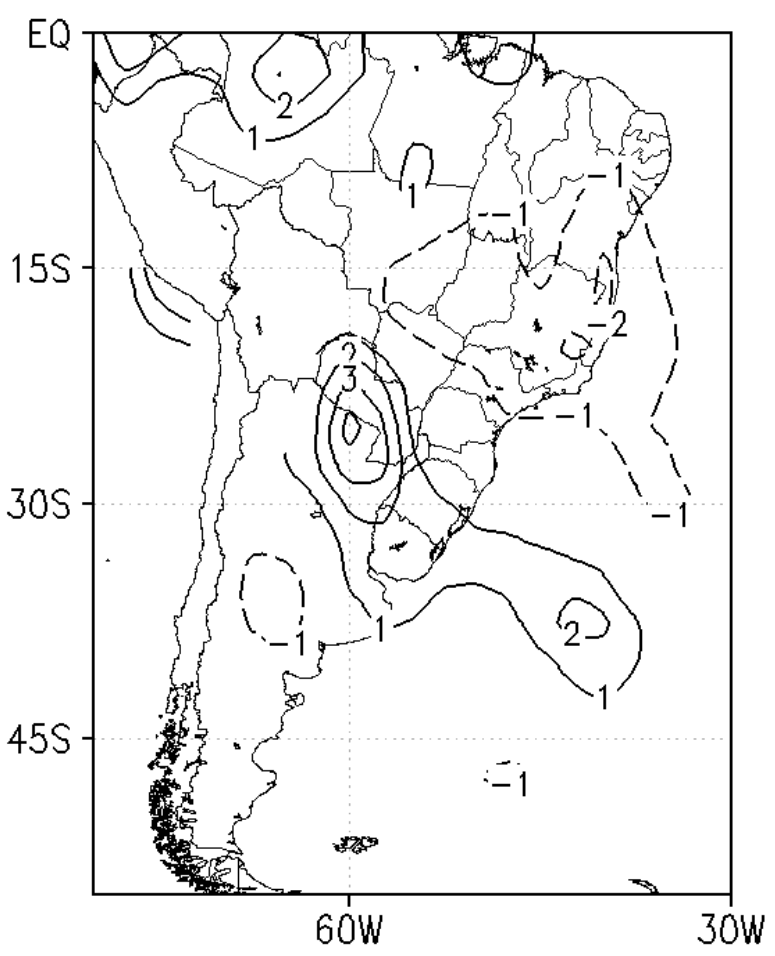

(b)

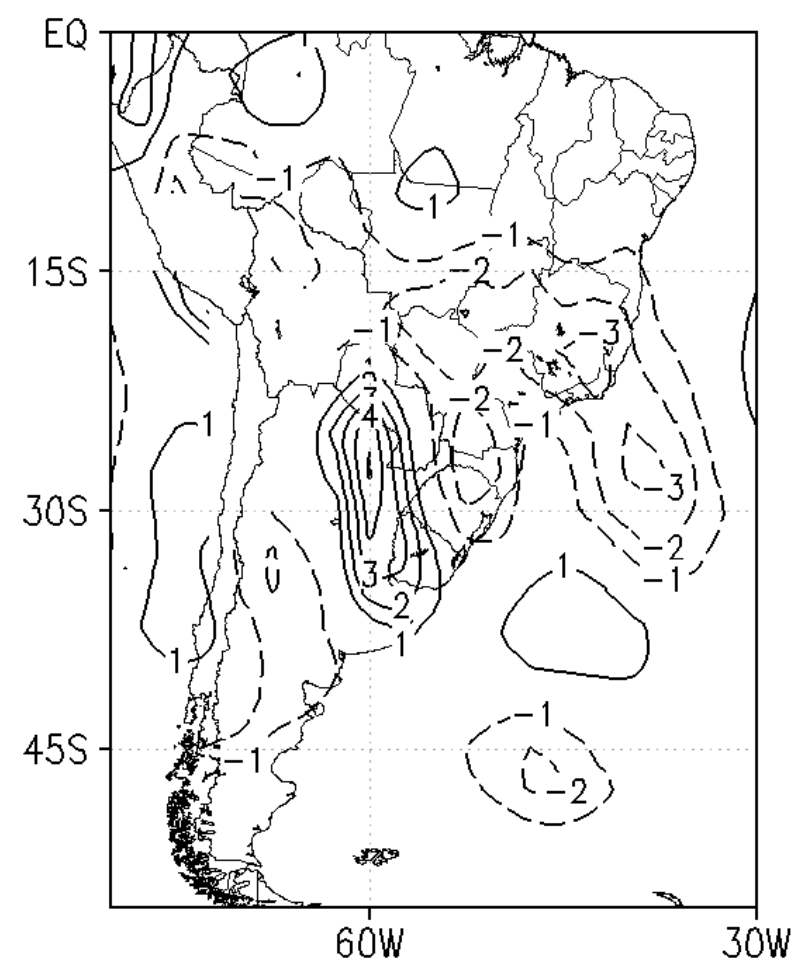

(d)

Fig. 16. Five-day mean fields of vertical advection of humidity $\left(\mathrm{g} \mathrm{kg}^{-1} \mathrm{day}^{-1}\right)$ in the development stage of the WDS: (a) $700 \mathrm{hPa}$, Case 29 , (b) $700 \mathrm{hPa}$, Case 32, (c) $850 \mathrm{hPa}$, Case 29, and (d) $850 \mathrm{hPa}$, Case 32. 


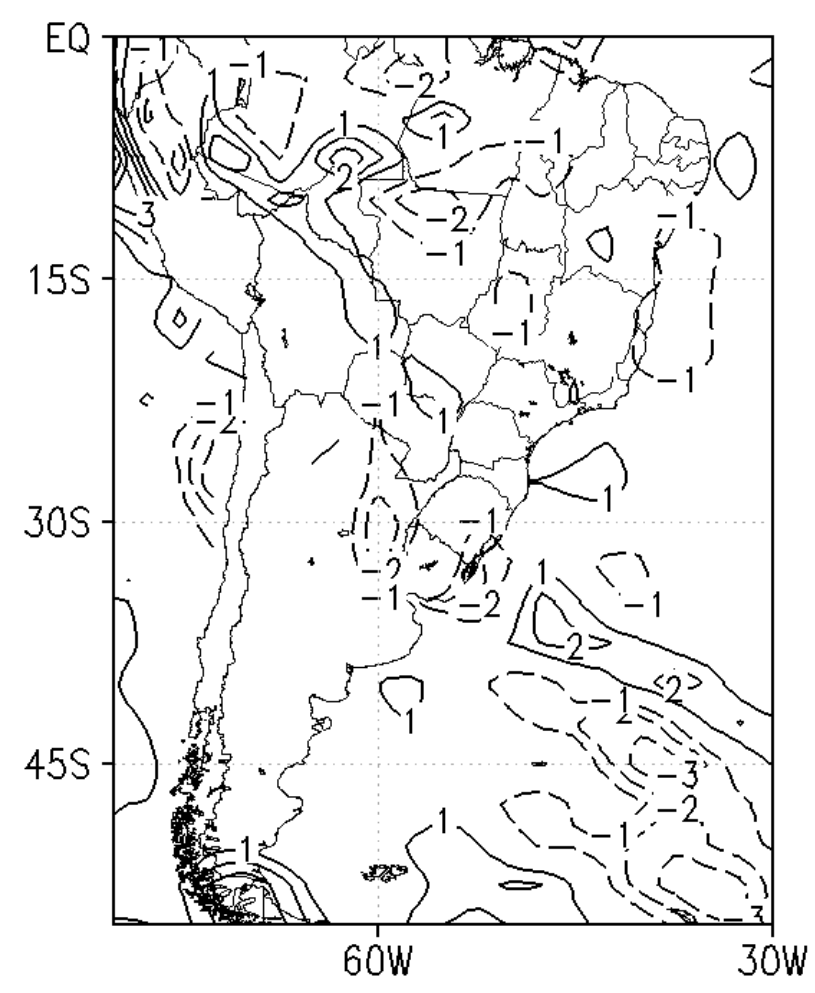

(a)

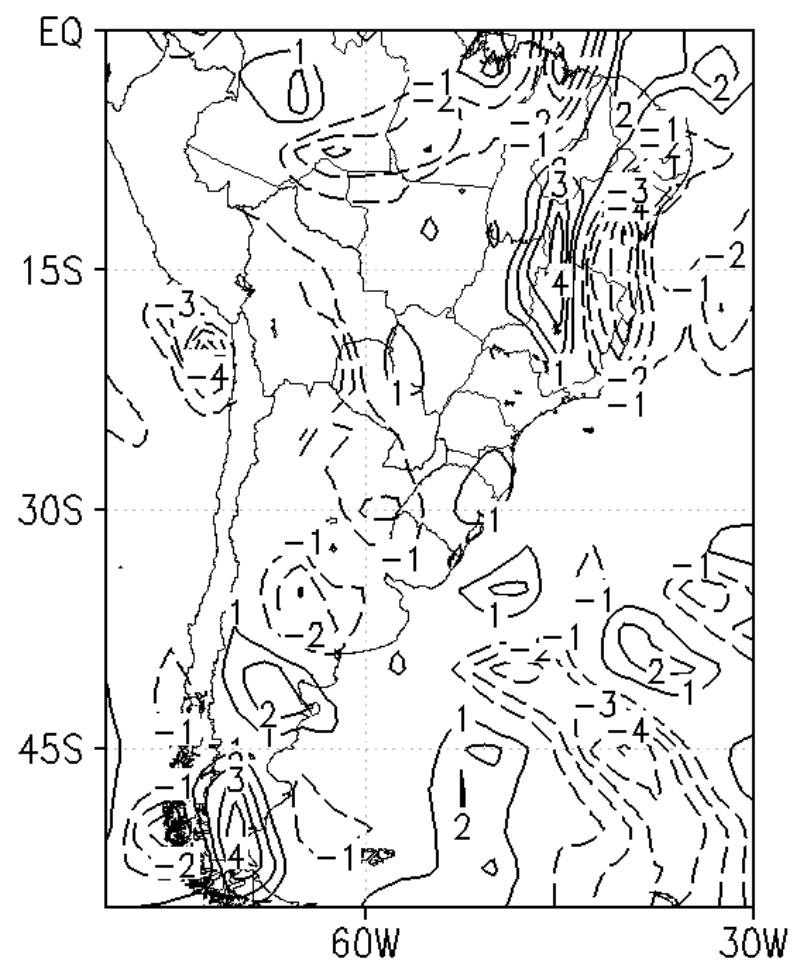

(c)

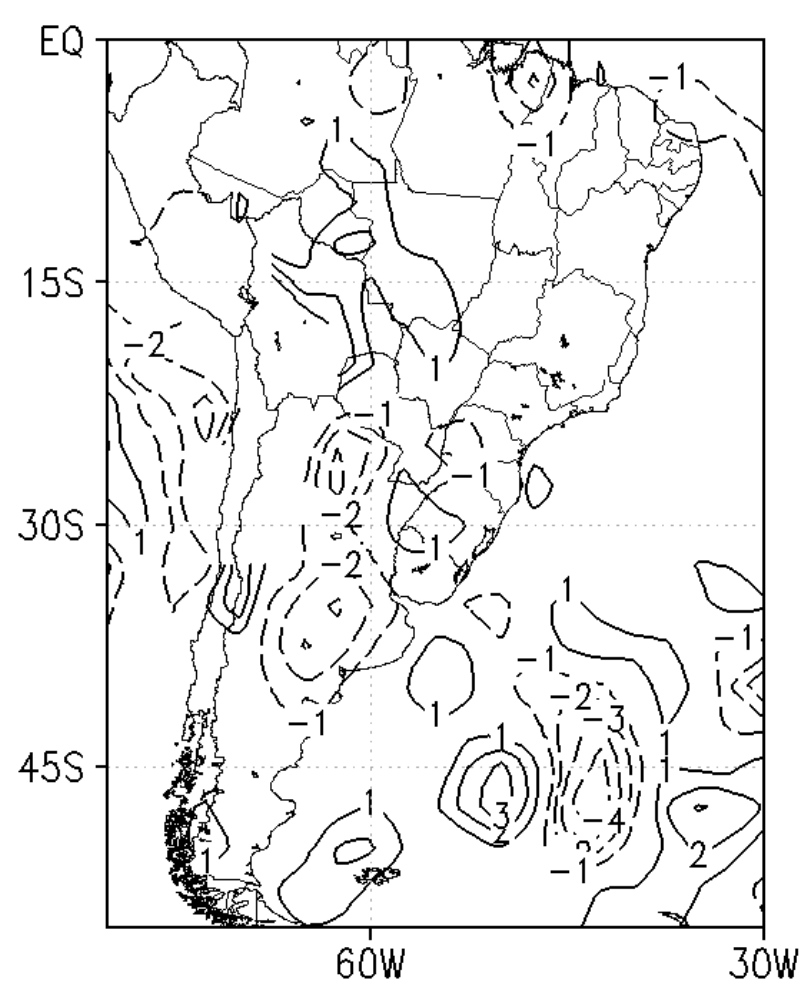

(b)

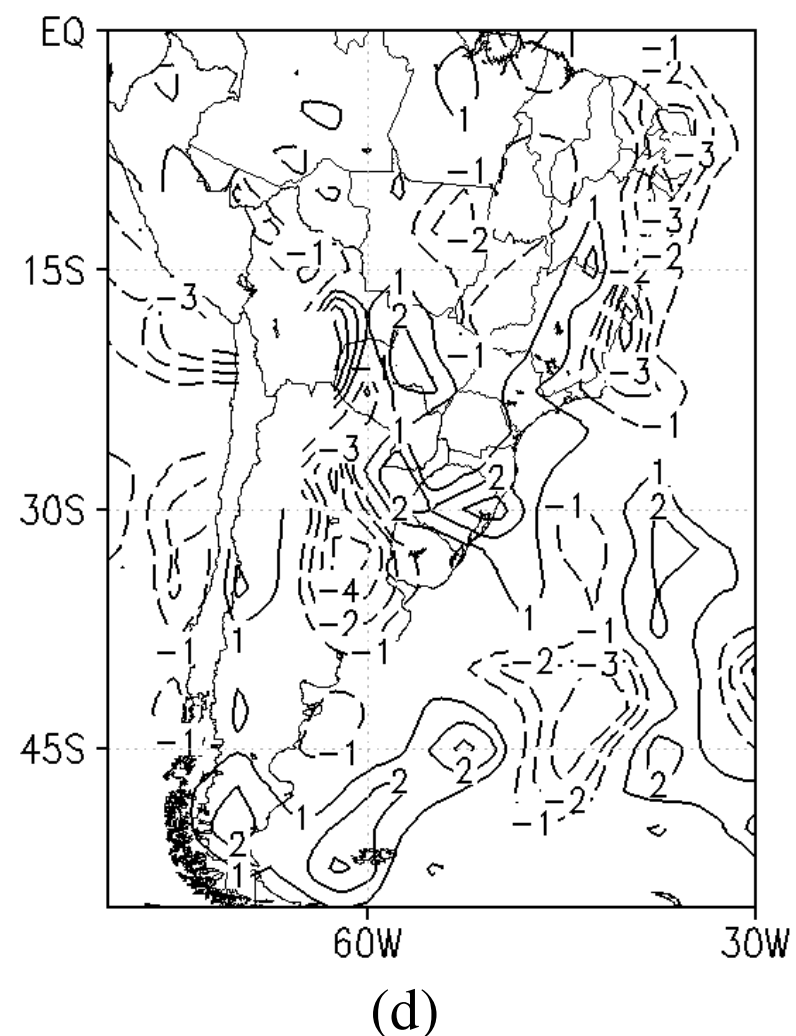

Fig. 17. Same as in Fig. 16, except for the fields of horizontal advection of humidity. 


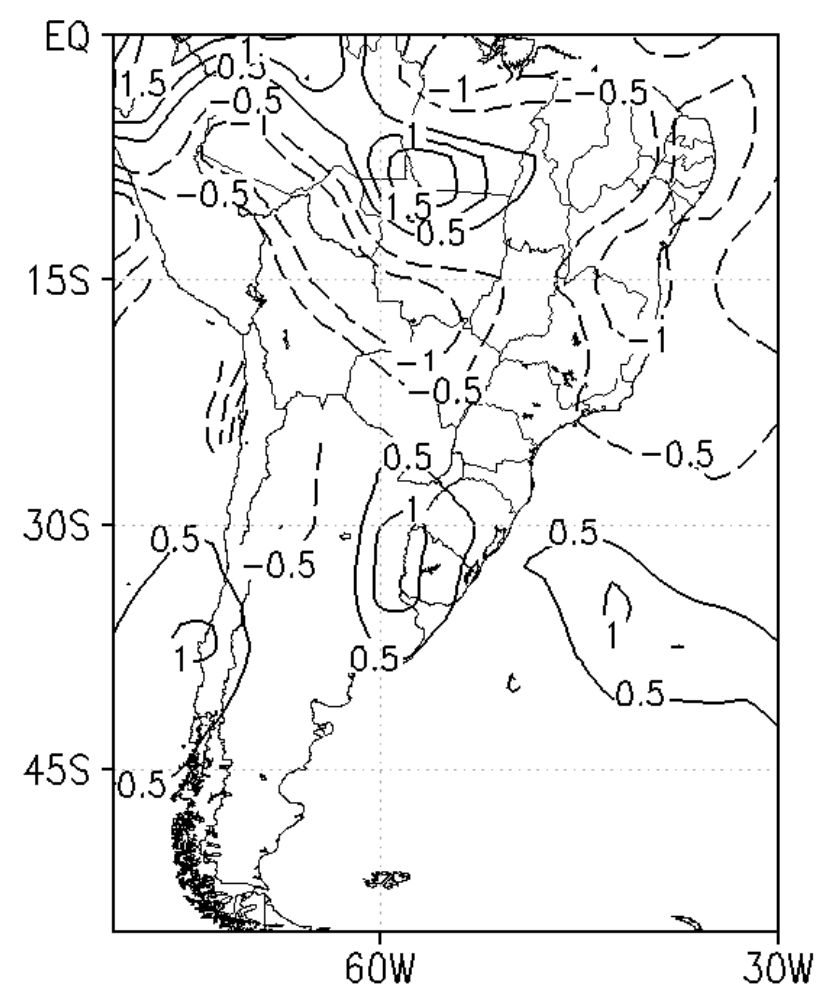

(a)

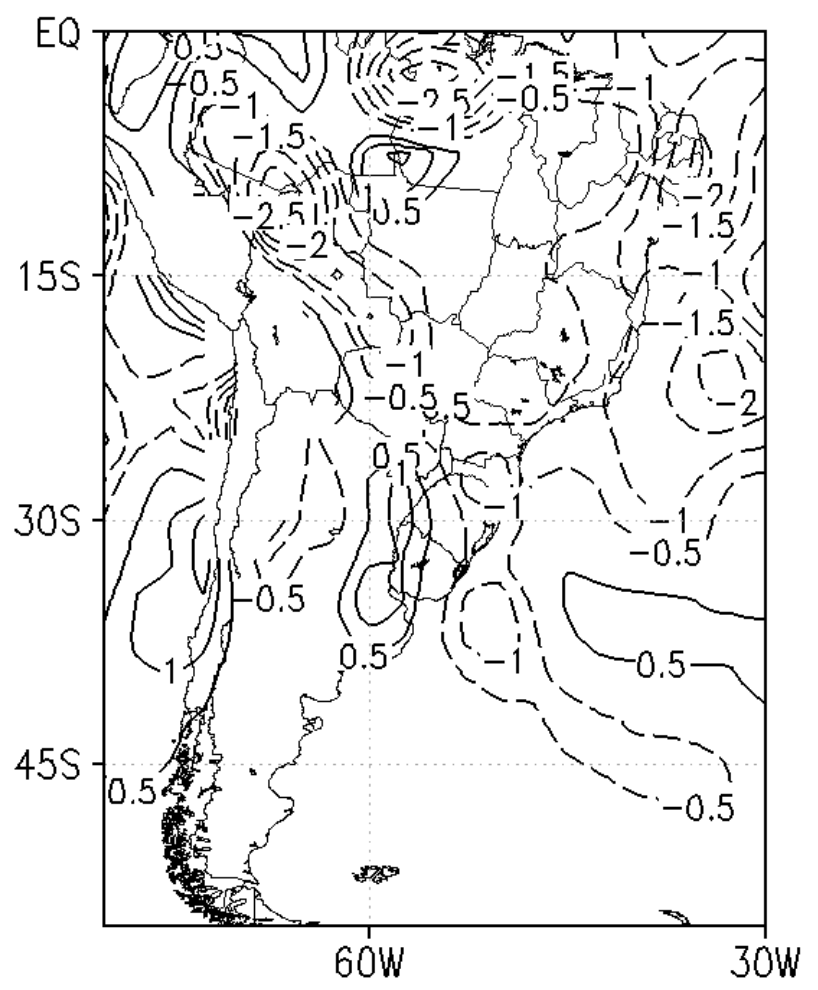

(c)

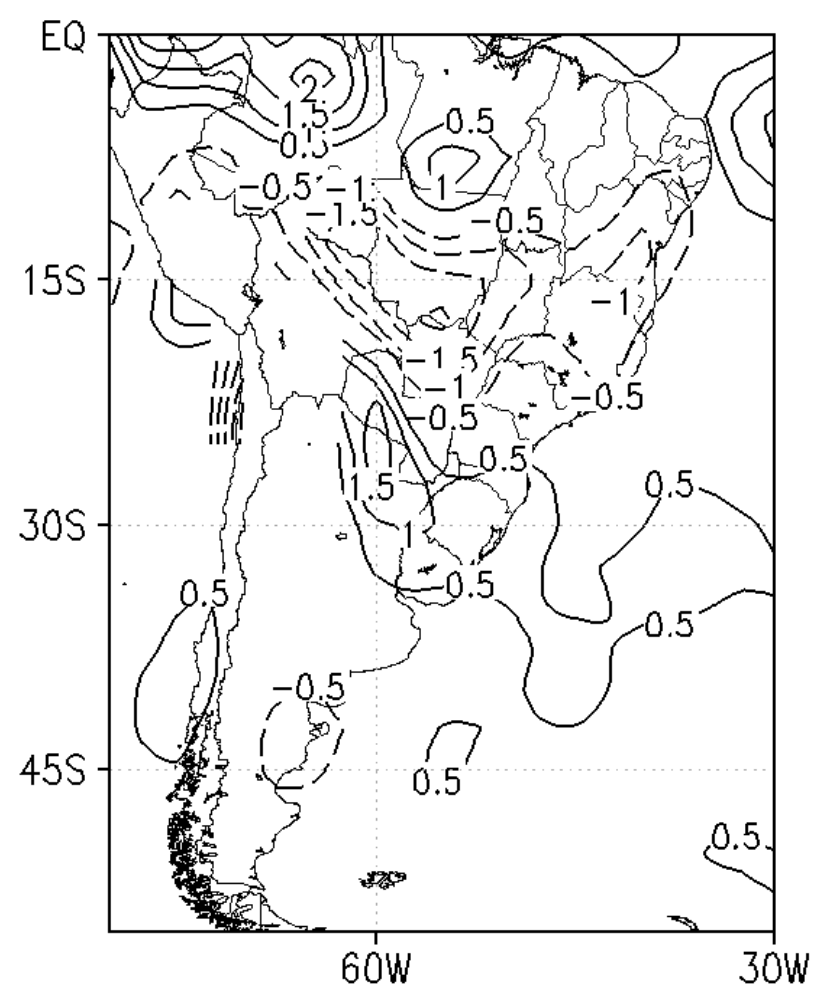

(b)

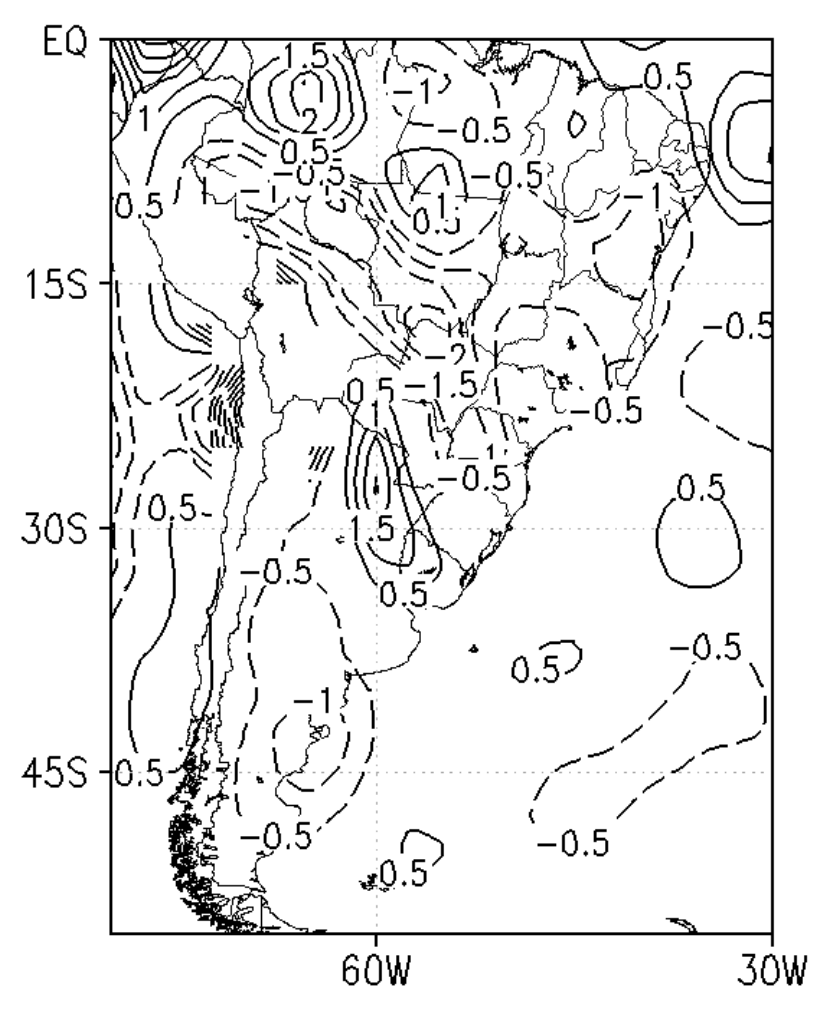

(d)

Fig. 18. Episode-mean fields vertical advection of humidity $\left(\mathrm{g} \mathrm{kg}^{-1} \mathrm{day}^{-1}\right)$ : (a) $700 \mathrm{hPa}$, Case 29 , (b) $700 \mathrm{hPa}, \mathrm{Case} 32$, (c) $850 \mathrm{hPa}$, Case 29, and (d) $850 \mathrm{hPa}$, Case 32. 


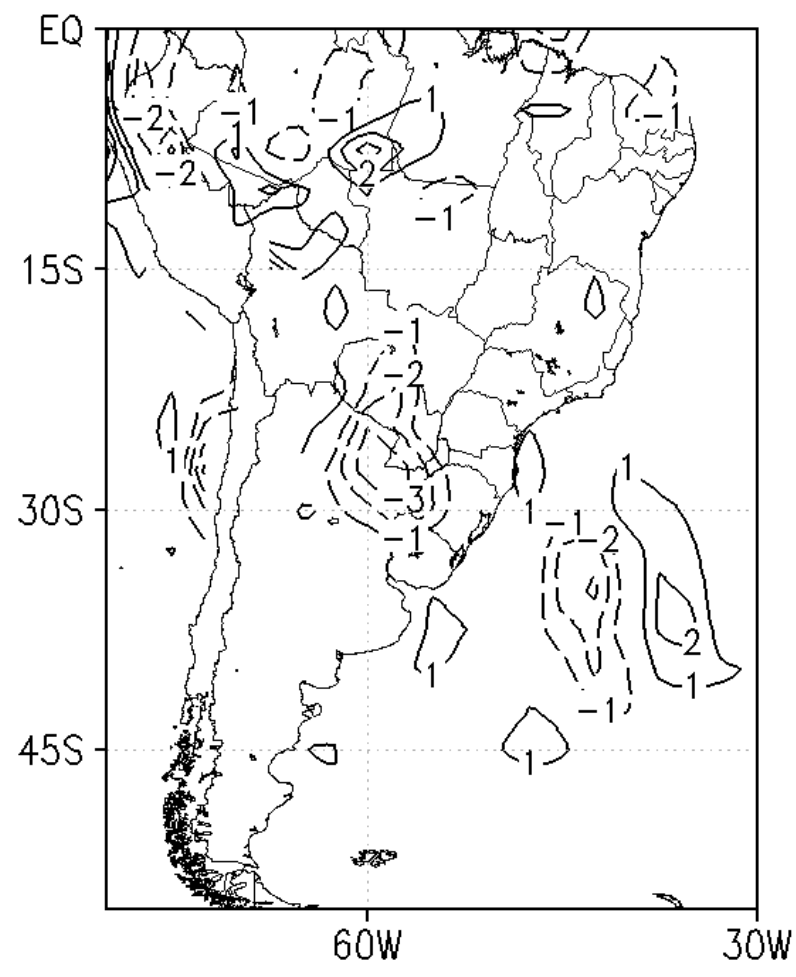

(a)

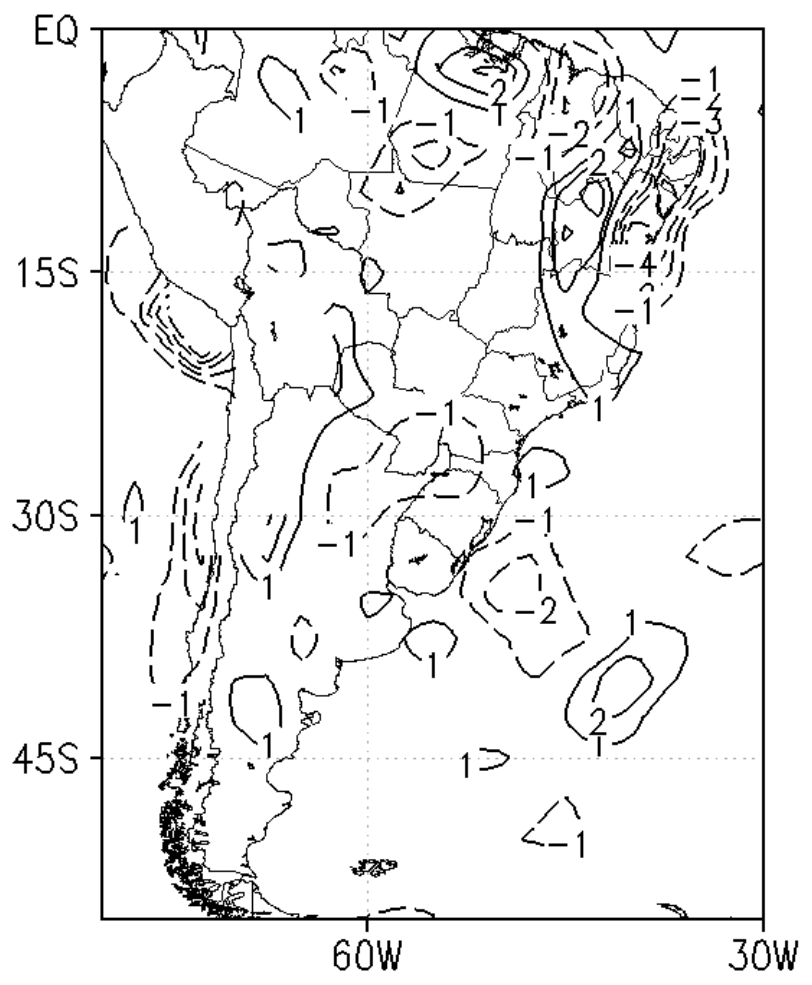

(c)

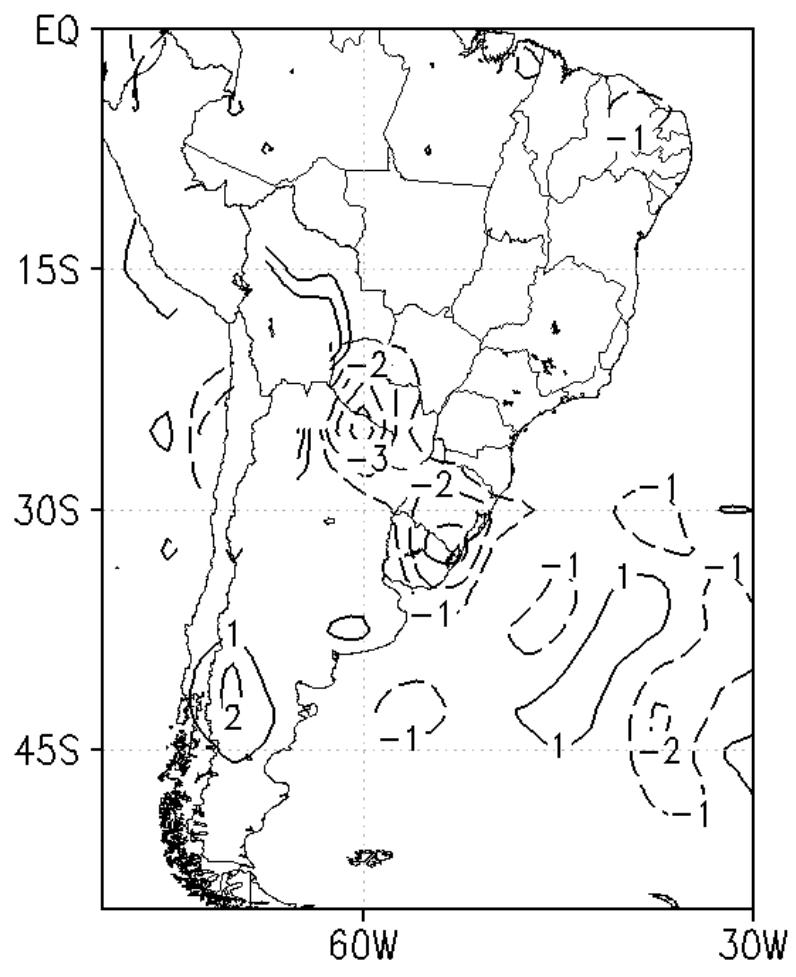

(b)

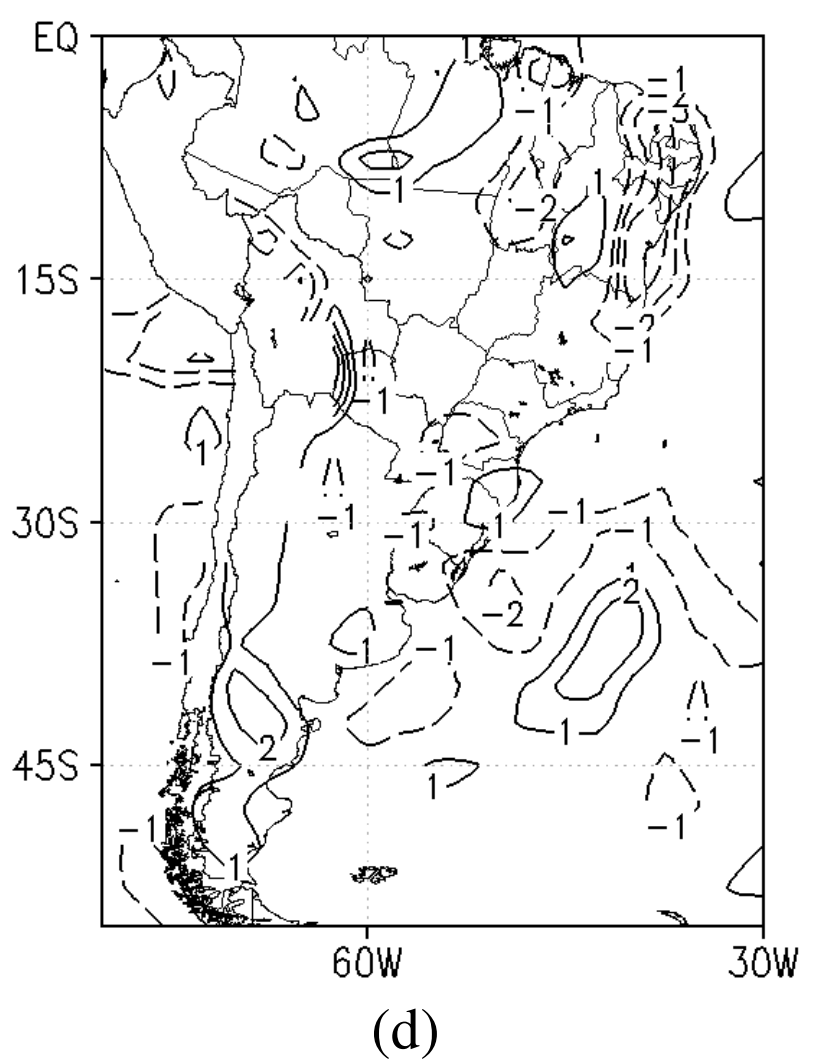

Fig. 19. Same as in Fig. 18 except for fields of horizontal advection of humidity. 


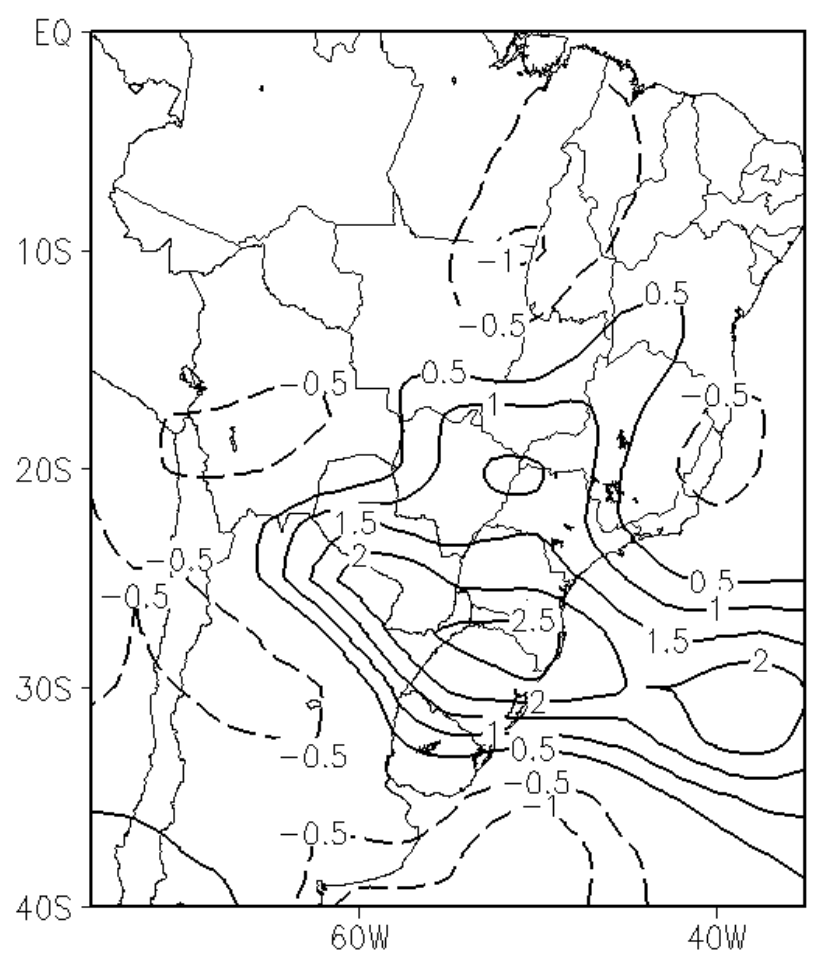

(a)

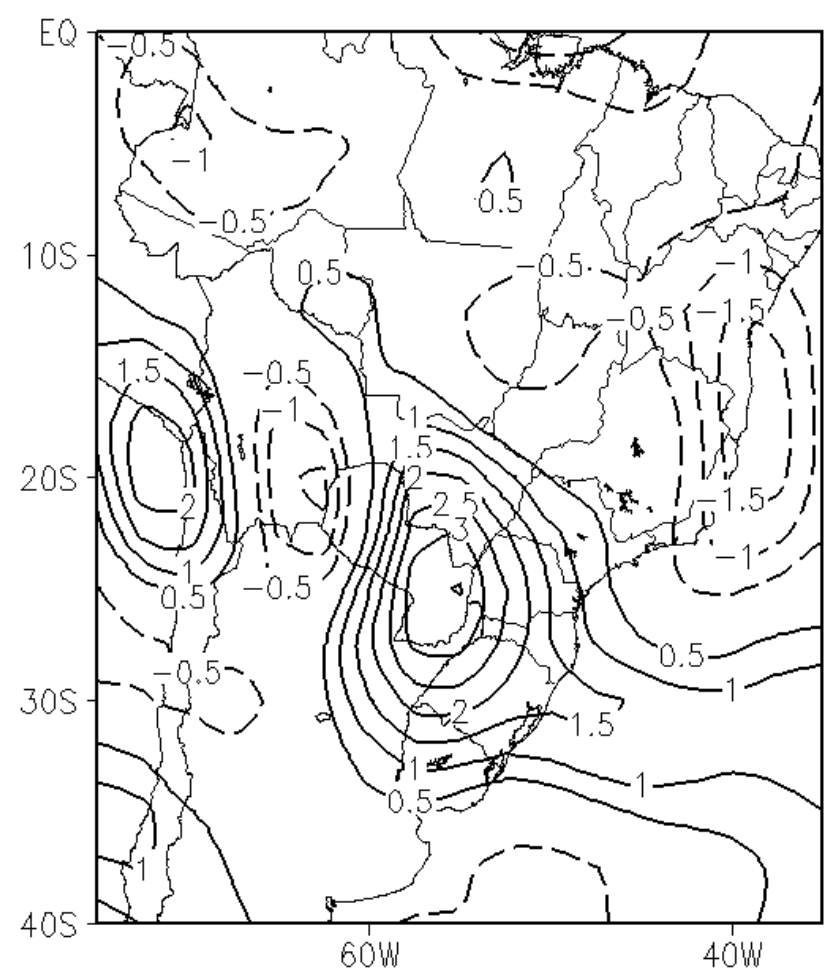

(b)

Fig. 20. Composite fields of (a) horizontal thermal advection and (b) vertical thermal advection, at $850 \mathrm{hPa}$ for the $17 \mathrm{strongest}$ WDSs. Units are in ${ }^{\circ} \mathrm{C}$ day $^{-1}$.

than the subtropical and tropical regions of South America the temperature and relative humidity anomalies averaged over the target area can be regarded as representative of the generalized dry and warm conditions over the central parts of the continent.

The warm and dry spells (WDSs) have life periods of one to two weeks and during this period the mean surface temperature over a wide area can be several degrees (up to $7^{\circ} \mathrm{C}$ ) warmer and the relative humidity up to $20 \%$ drier. The specific humidity anomaly at $1000 \mathrm{hPa}$ can reach $-3.0 \mathrm{~g} \mathrm{~kg}^{-1}$ in central Brazil in some cases of strong WDSs.

The frequency of occurrence of WDS (of the strength considered in this study) is found to be about 0.8 per year during the months of JJAS and the mean duration is about 11 days. There is a large interannual variability in the occurrence of WDS. Some years presented 3 events and some years did not present any event. The number of cases of WDSs during the La Niña years (12 out of 33) is less than the number during El Niño years (15). The neutral years presented only 10 cases. One reason for this is that the numbers of La Niña years and neutral years since 1961, as counted from the list given by NOAA (http://www.cpc.noaa.gov/products/), are less than the number of the El Nño years. This shows that there is no apparent relation between the occurrence of WDS and the phase of the ENSO phenomenon. This indicates that the WDS are a manifestation of the regional and synoptic scale perturbations.

A severity index of these events (SI) is defined as the sum of the area-averaged normalized positive temperature anomaly and negative relative humidity anomaly over the target area shown in Fig. 1. The composites of the 17 strong WDSs in terms of SI $(\geq 3.9)$ showed many interesting atmospheric flow features that can be considered as the signature of such events. The 1000-hPa temperature anomaly field presents a large positive area of several ${ }^{\circ} \mathrm{C}$ over the central parts of South America, showing that the phenomenon is nearly of continental proportions. The negative relative humidity anomalies likewise cover a large area in central South America. A low-pressure area at the surface and a ridge at the 500-hPa level over the central parts of South America are in conformity with the temperature distribution. Large scale subsidence north of $20^{\circ} \mathrm{S}$ and ascending motion south of $20^{\circ} \mathrm{S}$ in the middle troposphere, along with the poleward component of winds in the lower troposphere over Bolivia, central-western Brazil and Paraguay, show that the Hadley circulation during the WDSs is either weakened or even reversed. On the whole, the regional circulation during the WDSs in austral winter acquires summertime characteristics. 
The two cases of WDS presented in Sects. 4 and 5 show many interesting synoptic- and regional-scale characteristics associated with the episodes. The midtropospheric circulation in the eastern South Pacific Ocean shows a slow moving strong ridge south of $45^{\circ} \mathrm{S}$ and a relative low-pressure area to its north, resembling a blocking-like situation. The surface pressure also shows similar features. The South Atlantic subtropical high is seen to be located closer to the continent during and before the episodes. In the development stage (the five-day period around the first day of the WDS), a low-pressure area at the surface east of the Andes, with an associated frontal boundary over Uruguay, develops. This low pressure area in the central parts of the continent and the shift of the Atlantic subtropical high towards the continent strengthen northerly winds over the eastern half of South America. These winds provide warm advection. The frontal boundary moves slowly, during the WDSs, over the Atlantic Ocean without affecting the central parts of Brazil.

The warm and dry air mass associated with the WDS is fairly deep, occupying the lower troposphere from the surface up to $700 \mathrm{hPa}$. During the episode and, especially, in the development stage of the WDS, widespread subsidence in the middle and lower troposphere is observed over tropical and subtropical Brazil north of $22^{\circ} \mathrm{S}$, which causes drying and warming of the lower tropospheric air. The drying values are of the order of $1 \mathrm{~g} \mathrm{~kg}^{-1} \mathrm{day}^{-1}$ and the adiabatic warming is $2-4^{\circ} \mathrm{Cday}^{-1}$ over the central parts of Brazil in the development stage. The causes of the subsidence are not investigated in this study. A study of the east-west and northsouth (Walker type and Hadley type) circulations in the vertical plane over the global tropical and subtropical belts during and before the WDS episodes is necessary in order to understand the reasons for the subsidence.

The effects of subsidence on the warming and drying of the lower tropospheric air over the central parts of Brazil (over the target area) are more pronounced than the effects of horizontal advections, especially in the development stage of the WDS. The study of both the humidity parameters, specific humidity (q) and relative humidity (r), is necessary for understanding the WDS, because the water stress on the vegetation depends mostly on $r$ and the drying effect of the subsidence is seen in the q field.
Towards the end of the WDS a mid-tropospheric trough intensification and movement over the continent supports the formation of a new cold frontal boundary. This front penetrates into central Brazil, bringing cold advection in its wake, causing the dissipation of the anomalous situation.

Table 1 provides information for future verification of the impacts of WDS on socioeconomic problems, such as atmospheric pollution, human discomfort, respiratory ailments, scarcity of water resources and scarcity of hydroelectric energy in the central parts of the continent. Such studies are beyond the scope of the present investigation.

Acknowledgements. The authors wish to thank the anonymous reviewers for their valuable comments and suggestions.

Topical Editor F. D' Andrea thanks two referees for their help in evaluating this paper.

\section{References}

Assad, E. D., Sano, E. E., Matsumoto, R., Castro, L. H., and Silva, F. A. M.: Veranicos na região dos Cerrados Brasileiros: Frequiência e probabilidade de ocorrência (Little summers in the Brazilian Cerrado region: Frequency and probability of occurrence.), Pesquisa Agropecuária Brasileira, 28, 993-1003, 1993.

Braga, A. L. F., Conceição, G. M. S., and Pereira, L. A. A.: Air pollution and pediatric respiratory hospital admissions in São Paulo, J. Environ. Med., 1, 95-102, 2000.

DNMET: Normais Climatológicas (1961-1990), (Climatological Normals, 1961-1990.) Serviço de produção de Informação SPI/EMBRAPA, Brasília, available from Instituto Nacional de Meteorologia, Brasília, DF, Brazil, 84 pp, 1992.

Figueroa, S. N.: Estudo dos sistemas de circulação de verão sobre América do Sul e suas simulações com modelos numéricos, $\mathrm{PhD}$ Thesis, INPE, São José dos Campos, Brazil, 181 pp, 1997.

Lejenas, H.: Characteristics of Southern Hemisphere blocking as determined from long time series of observational data, Quart. J. Roy. Meteorol. Soc., 110, 967-979, 1984.

Satyamurty, P., Nobre, C. A., and Silva Dias, P. L.: South America: Tropics, in: Meteorology of the Southern Hemisphere, American Meteorological Society, 119-139, 1998. 